\title{
Strategic Planning with Critical Success Factors and Future Scenarios: An Integrated Strategic Planning Framework
}

\author{
Linda Parker Gates
}

November 2010

TECHNICAL REPORT

CMU/SEI-2010-TR-037

ESC-TR-2010-102

Acquisition Support Program

Unlimited distribution subject to the copyright.

http://www.sei.cmu.edu

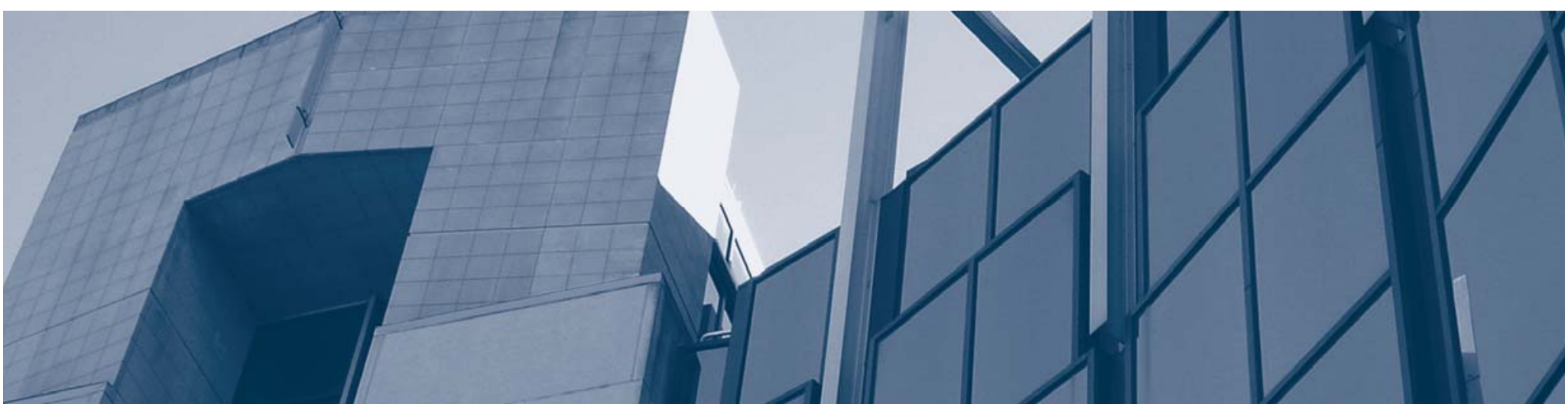


This report was prepared for the

SEI Administrative Agent

$\mathrm{ESC} / \mathrm{XPK}$

5 Eglin Street

Hanscom AFB, MA 01731-2100

The ideas and findings in this report should not be construed as an official DoD position. It is published in the interest of scientific and technical information exchange.

This work is sponsored by the U.S. Department of Defense. The Software Engineering Institute is a federally funded research and development center sponsored by the U.S. Department of Defense.

Copyright 2010 Carnegie Mellon University.

\section{NO WARRANTY}

THIS CARNEGIE MELLON UNIVERSITY AND SOFTWARE ENGINEERING INSTITUTE MATERIAL IS FURNISHED ON AN “AS-IS” BASIS. CARNEGIE MELLON UNIVERSITY MAKES NO WARRANTIES OF ANY KIND, EITHER EXPRESSED OR IMPLIED, AS TO ANY MATTER INCLUDING, BUT NOT LIMITED TO, WARRANTY OF FITNESS FOR PURPOSE OR MERCHANTABILITY, EXCLUSIVITY, OR RESULTS OBTAINED FROM USE OF THE MATERIAL. CARNEGIE MELLON UNIVERSITY DOES NOT MAKE ANY WARRANTY OF ANY KIND WITH RESPECT TO FREEDOM FROM PATENT, TRADEMARK, OR COPYRIGHT INFRINGEMENT.

Use of any trademarks in this report is not intended in any way to infringe on the rights of the trademark holder.

Internal use. Permission to reproduce this document and to prepare derivative works from this document for internal use is granted, provided the copyright and "No Warranty" statements are included with all reproductions and derivative works.

External use. This document may be reproduced in its entirety, without modification, and freely distributed in written or electronic form without requesting formal permission. Permission is required for any other external and/or commercial use. Requests for permission should be directed to the Software Engineering Institute at permission@sei.cmu.edu.

This work was created in the performance of Federal Government Contract Number FA8721-05-C-0003 with Carnegie Mellon University for the operation of the Software Engineering Institute, a federally funded research and development center. The Government of the United States has a royalty-free government-purpose license to use, duplicate, or disclose the work, in whole or in part and in any manner, and to have or permit others to do so, for government purposes pursuant to the copyright license under the clause at 252.227-7013.

For information about SEI publications, please visit the library on the SEI website (www.sei.cmu.edu/library/). 


\section{Table of Contents}

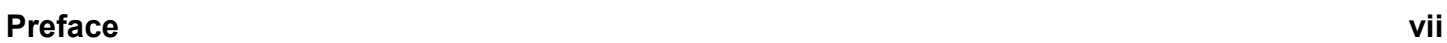

Acknowledgements $\quad$ ix

Executive Summary $\quad$ xi

Abstract $\quad$ xiii

1 Introduction 1

1.1 Purpose and Structure of this Report 1

1.2 Background

$\begin{array}{ll}1.3 \text { The Strategic Planning Landscape } & 1\end{array}$

2 Strategic Planning $\quad 3$

2.1 Strategic Planning $\quad 3$

2.2 Strategic Planning Elements $\quad 4$

2.3 Strategic Planning and Organizational Hierarchy 6

3 Critical Success Factors $\quad 9$

$\begin{array}{ll}3.1 \text { Critical Success Factors } & 9\end{array}$

$\begin{array}{lr}3.2 \text { CSF Characteristics } & 9\end{array}$

3.3 The Critical Success Factor Method 11

4 Future Scenarios $r$

$\begin{array}{llr}4.1 & \text { Future Scenarios } & 13\end{array}$

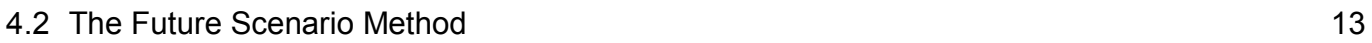

$\begin{array}{ll}4.3 \text { General Limitations of Scenario Planning } & 19\end{array}$

$5 \quad$ Integrating Critical Success Factors and Future Scenarios with Strategic Planning 21

$\begin{array}{ll}5.1 \text { Strategic Thinking } & 21\end{array}$

$\begin{array}{ll}5.2 \text { The Strategy Paradox } & 22\end{array}$

5.3 Integrating Critical Success Factors and Future Scenarios with Strategic Planning 23

$\begin{array}{ll}5.4 \text { Linking CSFs and Scenarios } & 30\end{array}$

6 Special Considerations for IT Strategy $\quad 31$

$\begin{array}{ll}6.1 \text { IT Strategic Planning } & 31\end{array}$

6.2 IT Critical Success Factors $\quad 32$

$\begin{array}{ll}6.3 \text { IT Future Scenarios } & 34\end{array}$

7 Conclusions $\quad 35$

$\begin{array}{ll}7.1 \text { Applicability } & 35\end{array}$

$\begin{array}{ll}7.2 \text { Limitations } & 36\end{array}$

$\begin{array}{ll}7.3 \text { Future Work } & 36\end{array}$

$\begin{array}{llr}\text { Appendix A } & \text { CSF Method Application Notes } & 39\end{array}$

$\begin{array}{lll}\text { Appendix B Scenario Planning Application Notes } & 43\end{array}$

$\begin{array}{llr}\text { Appendix C } & 45\end{array}$

$\begin{array}{lr}\text { References } & 47\end{array}$ 
SOFTWARE ENGINEERING INSTITUTE | ii 


\section{List of Figures}

Figure 1: Typical Strategic Planning Elements 4

Figure 2: Critical Success Factor Hierarchy 10

Figure 3: $\quad$ Example Driving Forces for Government Health Care 14

Figure 4: Example Critical Uncertainties for Government Health Care 15

Figure 5: Example Government Health Care Scenario Matrix 16

Figure 6: Example Government Health Care Scenarios with Narrative Titles 17

Figure 7: $\quad$ Example Government Health Care Scenarios with Implications 18

Figure 8: The Strategic Process: Strategic Planning and Strategic Thinking 22

Figure 9: Critical Success Factors and Future Scenarios with Typical Strategic Planning Elements 24

Figure 10: Critical Success Factor Levels and Strategic Planning 26

Figure 11: CSF Relationships with Strategic Planning Elements 27

Figure 12: Future Scenario Relationships with Other Strategic Planning Elements 29

Figure 13: Context for IT Strategy 32

Figure 14: Critical Success Factors and IT Strategy 34

Figure 15: $\quad$ Future Scenarios and IT Strategy 34

Figure 16: Enhanced Strategic Planning in Context 35 
SOFTWARE ENGINEERING INSTITUTE | iv 


\section{List of Tables}

Table 1: $\quad$ Strategic Planning Terms $\quad 5$

Table 2: $\quad$ Parsons/Thompson Model of Organizational Structure $\quad 7$ 
SOFTWARE ENGINEERING INSTITUTE | vi 


\section{Preface}

This report explores the value of enhancing typical strategic planning techniques with the critical success factor (CSF) method and scenario-based planning and presents an integrated framework for strategic planning. Strategic planning, CSFs, and scenario planning all require expertise in the particular method. Expertise in the domain where the techniques will be applied (e.g., organizational strategy, information technology [IT] strategy, security management) is also advised.

Although this report describes insights gained from recent work with CSFs, scenarios, and strategic planning, the experiences described in this report derive from limited engagements and therefore cannot be fully generalized. However, the conclusions presented here reflect insights that will be useful in subsequent efforts to integrate CSFs and scenarios with strategic planning efforts and further validate the information framework. 


\section{Acknowledgements}

Many people contributed to this report by supporting the work that led to it. Those people include Rita Creel, Eileen Forrester, Mark Kasunic, Bill Novak, Steve Palmquist, Kate Ambrose Sereno, Gian Wemyss, and David White.

I would like to acknowledge the excellent research assistance provided by Sheila Rosenthal. I am very thankful for the astute comments offered by my reviewers: Rich Caralli, Bill Novak, Steve Palmquist, and Mary Catherine Ward. I greatly appreciate the technical editing provided by Bill Thomas and Murray Connelly.

Finally, I would like to thank the Carnegie Mellon ${ }^{\circledR}$ Software Engineering Institute (SEI) and the sponsors of this work: Bill Novak, Tricia Oberndorf, Steve Palmquist, Terry Roberts, and Mary Catherine Ward.

(8) Carnegie Mellon is registered in the U.S. Patent and Trademark Office by Carnegie Mellon University. 
SOFTWARE ENGINEERING INSTITUTE | x 


\section{Executive Summary}

Although the purpose of strategic planning is straightforward - to outline where an organization wants to go and how it's going to get there-its nature is complex and dynamic. Two techniques, the critical success factor (CSF) method and future scenario planning, can augment strategic planning efforts by illuminating an organization's present situation and potential future. This report explores the value of enhancing typical strategic planning techniques with the CSF method and scenario-based planning and presents an integrated framework for helping organizations understand the broad range of interrelated elements that influence strategy development.

Critical success factors are defined as the handful of key areas where an organization must perform well on a consistent basis to achieve its mission. CSFs can be derived through a document review and analysis of the goals and objectives of key management personnel, as well as interviews with those individuals about their specific domain and the barriers they encounter in achieving their goals and objectives.

Future scenarios allow organizations to explore multiple potential futures and generate robust strategies and early warning signs to understand how the future is unfolding. Where a vision articulates a "preferred future," future scenarios describe how an organization might achieve its mission in different circumstances or environments. Organizations identify a focal issue or major decision the organization faces and the critical uncertainties in the macro environment, such as social, economic, political, environmental, and technical forces. Scenarios are developed based on combinations of these forces and robust strategies are identified to address multiple futures. Finally, indicators are identified to help understand how the future is affecting the organization's decisions.

The Carnegie Mellon ${ }^{\circledR}$ Software Engineering Institute (SEI) began exploring the synergy between CSFs and future scenarios in the strategic planning context in 2005 and has assisted several organizations in using an integrated framework over the past four years. The report synthesizes documented theory and research in strategic planning, CSFs, and scenarios and provides insights and lessons regarding the value and limitations of the integrated strategic planning framework. The report includes considerations for applying this approach in the context of strategic planning for information technology.

Suggestions for future work include

- $\quad$ exploring the use of IT or security scenarios in unit-level planning and organizational strategic planning

- creating an integrated strategic planning process to support the integrated farmework

- connecting CSFs and scenarios directly to one another in the monitoring stages of an integrated strategic planning process.

${ }^{\circledR}$ Carnegie Mellon is registered in the U.S. Patent and Trademark Office by Carnegie Mellon University. 
Two appendices provide notes from the SEI's experience applying the CSF method and scenario planning in the context of strategic planning. 


\section{Abstract}

This report explores the value of enhancing typical strategic planning techniques with the critical success factor (CSF) method and scenario planning. It synthesizes documented theory and research in strategic planning, CSFs, and future scenarios. It proposes an enhanced, integrated information framework for strategic planning that can help organizations understand the broad range of interrelated elements that influence strategy development. Finally, the report provides insights and lessons regarding the value and limitations of the integrated strategic planning framework and suggestions for future work. 


\section{Introduction}

Industry executives and analysts often mistakenly talk about strategy as if it were some kind of chess match. But in chess, you have just two opponents, each with identical resources, and with luck playing a minimal role. The real world is much more like a poker game, with multiple players trying to make the best of whatever hand fortune has dealt them.

- David Moschella ${ }^{1}$

\subsection{Purpose and Structure of this Report}

This report explores the value of enhancing typical strategic planning with the critical success factor (CSF) method and future scenarios. It synthesizes documented theory and research in strategic planning, CSFs, and future scenarios, and proposes an information framework for enhanced strategic planning.

This report does not advocate or articulate a specific strategic planning approach, though theories are discussed and pointers to published methods are provided. Nor does the report document the CSF and scenario planning methods; these methodologies are published elsewhere. ${ }^{2}$

\subsection{Background}

In 2005, the SEI began exploring the idea of pairing the CSF method with future scenarios in a strategic planning context. The SEI had previously used these techniques independently of one another in multiple engagements. ${ }^{3}$

In 2006 the SEI created an initial framework for integrating the information generated by these two techniques with information typically required for strategic planning. The initial pilot resulted in the development of a 10-year information technology (IT) strategic plan. Additional pilots have been conducted using pieces of the framework to develop one- to five-year organizational strategic plans.

\subsection{The Strategic Planning Landscape}

Strategic plans outline an organization's intended approach for achieving its mission. There are many ways to conduct strategic planning, most of which result in a plan or set of plans that articulate organizational goals and a high-level strategy for achieving them.

1 Moschella, David. "Ten Key IT Challenges for the Next 20 Years," Computerworld, December 1999.

2 The CSF method is documented in a report by Richard Caralli; the future scenario method is described in Scenarios: The Art of Strategic Conversation [Caralli 2004, van der Heijden 1996].

3 Scenario planning exercises were led by Global Business Network (GBN). 
CSFs and future scenarios both have extensive histories with operational and strategic planning. The CSF method results in an identified set of organizational critical success factors that represent key performance areas that are essential for the organization to accomplish its mission. Scenario planning explores multiple potential futures and generates multiple robust strategies (not complete strategic plans) and a set of early-warning signs that help an organization understand how the future is unfolding. In addition, both CSFs and scenarios provide processes that help an organization establish strong ways of thinking, communicating, and making decisions. Neither method, however, constitutes a strategic planning effort, results in a strategy or strategic plan per se, or has a direct, explicit interface with strategic planning. 


\section{Strategic Planning}

In strategy it is important to see distant things as if they were close and to take a distanced view of close things.

-Miyamoto Musashi, samurai warrior ${ }^{4}$

\subsection{Strategic Planning}

Strategic planning is the process of defining an organization's plans for achieving its mission. An organizational strategy is a derived approach to achieving that mission. The product of a strategic planning effort is typically a document (a strategic plan) that elaborates a high-level strategy and articulates the elements that influence it - it is a full description of the organizational environment and intentions. Note that a strategy is directional in nature; although descriptions and analysis of the present situation are included, a strategic plan does not merely endorse the status quo, it directs change of some kind [Cassidy 2006]. Division-level and organizational-unit-level planning should be tied directly to the organization's strategic plan.

Strategic planning is not only an important foundation for executing work; it also sets the stage for enterprise architecture, process improvement, risk management, portfolio management, and any other enterprise-wide initiatives.

There are many documented approaches to strategic planning. ${ }^{5}$ Typical strategic planning processes examine an organization's current environment and abilities (the present situation), considerations about how it would like to grow or evolve (the desired future), its aspirations as an organization (what it will strive to do), and its intentions for moving forward (how it will move forward). These high-level elements are described below:

- The What: These are descriptions of what the organization does and what it aspires to achieve — its organizational targets — including its goals, objectives, and quantitative performance measures.

- The Present: The present situation, or current environment, is typically described in terms of the organization's mission, guiding principles (or values), organizational strengths (or enablers), and organizational barriers (weaknesses or challenges).

- The Future: The desired future is described by the organizational vision and targets.

- The How: The preferred route to achieving the organizational goals, objectives, and mission is communicated as a strategy or as strategic goals. ${ }^{6}$

4 Musashi, Miyamoto. The Book of Five Rings: Classic Treaty on Military Strategy. Wildside Press, 2009.

5 One good example is the 1994 book Team-Based Strategic Planning: A Complete Guide to Structuring, Facilitating, and Implementing the Process by David Fogg [Fogg 1994].

6 Strategic goals typically reflect the primary goals of an organization or enterprise and imply a particular set of strategies. 
Figure 1 shows the typical strategic plan elements and their relationships to one another.

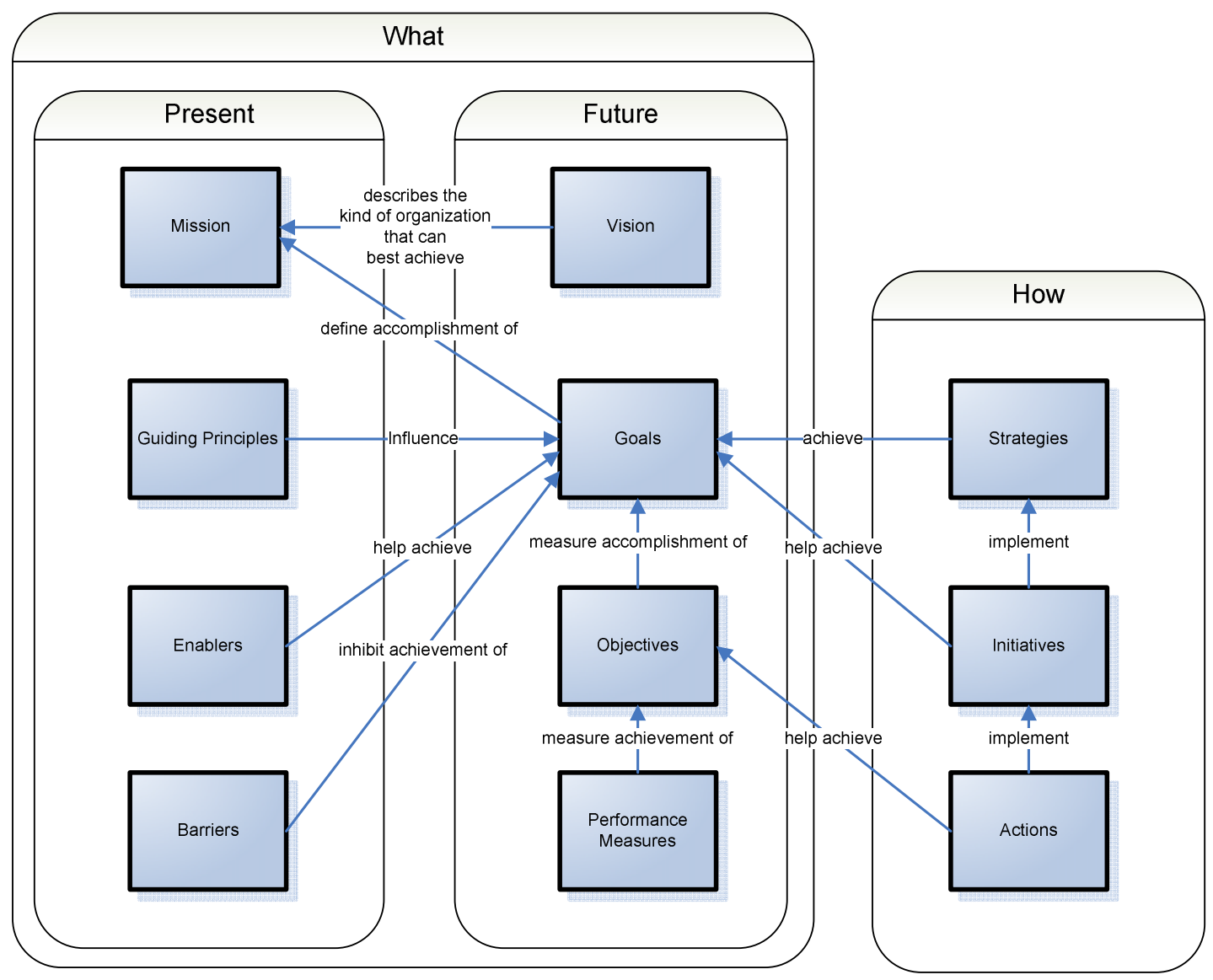

Figure 1: Typical Strategic Planning Elements

Note that goals and the steps to achieving them (i.e., the whats and hows) can take on a different tenor at different hierarchical levels of an organization. For example, an organizational strategy might serve as a set of goals for managerial staff, for which that staff will create a sub-strategy; that sub-strategy might translate into goals for technical or production staff.

\subsection{Strategic Planning Elements}

A well-documented strategic plan is critically important for organizing thinking and communicating thoughts. Strategic plans include elements that describe an organization's present state, aspirations, intentions for the future, and approach for going forward.

Table 1 contains the definitions of the terms typically used to describe strategic planning elements (see also Figure 1). Understanding these elements and their relationship to one another supports not only strategic thinking and planning, but also the effective use of CSFs and future scenarios in strategic planning efforts. 


\section{Table 1: $\quad$ Strategic Planning Terms}

\begin{tabular}{|c|c|}
\hline Term & Definition \\
\hline Mission & $\begin{array}{l}\text { An organization's mission is its primary business or purpose; it describes what an organiza- } \\
\text { tion does, for whom, and its benefit. The mission of an organization is not a time-bound objec- } \\
\text { tive. }\end{array}$ \\
\hline Vision & $\begin{array}{l}\text { A vision is an ideal that an organization intends to pursue. It links the organization to the fu- } \\
\text { ture by articulating instantiations of successful execution of the mission. An organization's } \\
\text { vision is a source of inspiration and can be broader than the organization's capabilities. It } \\
\text { might, in fact, describe what can be achieved in a broader environment if the organization and } \\
\text { others are successful in achieving their individual missions. }\end{array}$ \\
\hline Goals & Goals are broad, measurable, aims that support the accomplishment of a mission. \\
\hline Objectives & $\begin{array}{l}\text { Objectives are specific, quantifiable, lower-level targets that indicate an accomplishment of a } \\
\text { goal. }\end{array}$ \\
\hline $\begin{array}{l}\text { Guiding } \\
\text { Principles }\end{array}$ & $\begin{array}{l}\text { Guiding principles are directive statements that articulate the constraints an organization } \\
\text { chooses to place upon the way it achieves its goals. Guiding principles embrace core values } \\
\text { and are used to shape an organization's strategy. Guiding principles reflect long-term inten- } \\
\text { tions, but are not necessarily permanent. }\end{array}$ \\
\hline Enablers & $\begin{array}{l}\text { Enablers are external conditions or organizational strengths that facilitate an organization's } \\
\text { ability to accomplish its goals or objectives. }\end{array}$ \\
\hline Barriers & $\begin{array}{l}\text { Barriers are external conditions or organizational (internal) weaknesses that hinder an organ- } \\
\text { ization's ability to accomplish a goal or objective. }\end{array}$ \\
\hline Strategy & $\begin{array}{l}\text { A strategy is a derived approach to achieving the mission, goals, and objectives of an organi- } \\
\text { zation. It supports the organizational vision, takes into account organizational enablers and } \\
\text { barriers, and upholds its guiding principles. }\end{array}$ \\
\hline Strategic Plan & $\begin{array}{l}\text { A strategic plan is a document that results from a strategic planning activity. It elaborates the } \\
\text { organizational strategy and documents the elements that influence it. }\end{array}$ \\
\hline Initiative & An initiative is a specific set of actions that implement a strategy. \\
\hline Actions & $\begin{array}{l}\text { Actions are specific steps to achieve a goal or objective. Actions typically have assigned staff } \\
\text { and schedule constraints. }\end{array}$ \\
\hline $\begin{array}{l}\text { Performance } \\
\text { Measures }\end{array}$ & Performance measures describe performance targets relevant to each objective. \\
\hline
\end{tabular}

7 A guiding principle may seem similar in content to a goal but it lacks measurable aims. A guiding principle can generate a goal when an organization chooses to commit resources to achieving a measurable result regarding its content. 
As a partial example, consider the mission statement of the United States Postal Service (USPS) from its five-year strategic plan for fiscal years 2001-2005: "To bind the nation together through the correspondence of the people, to provide access in all communities, and to offer prompt, reliable postal services at uniform prices." In its vision statement, the USPS sought "to become an organization that can improve performance and affordability, implement innovative ways to grow both its revenues and those of the mailing industry, and find flexible, responsive solutions to the challenges raised by technology and the seismic shifts in the global postal business environment." This vision described the kind of organization the USPS believed it must be to fulfill its mission.

The guiding principles of "increased flexibility, innovation, and responsiveness" placed constraints on how the USPS would achieve its goals, which were presented from the perspective, or "voice," of the customer, the employee, and the business:

- "Voice of the customer: Earn customers' business in a marketplace where they have choices by providing them with world-class quality at competitive prices.

- "Voice of the employee: Foster an inclusive and welcoming workplace consistent with the values of fairness, opportunity, safety, and security; where everyone is given the knowledge, tools, education, and encouragement to be successful; and where everyone is recognized for and takes pride in his/her participation in customer and Postal Service success.

- "Voice of the business: Generate financial performance that assures the commercial viability of the Postal Service as a provider in a changing, competitive marketplace and to generate positive cash flow to finance high-yield investments for the future while providing competitively-priced products and services."

The plan also contained subgoals (objectives) and performance measures for each goal and outlined organizational strategies for making progress [USPS 2000].

\subsection{Strategic Planning and Organizational Hierarchy}

It is important when thinking about strategic planning to think about organizational hierarchy, both in terms of how the strategy will apply to the organization and in terms of the roles and responsibilities for planning.

Table 2 presents the Parsons/Thompson model of organizational structure, used to organize enterprise architecture concepts. The model identifies three general levels common to most organizations: the institutional (or organizational) level, the managerial level, and the technical level [Thompson 1967, Bernard 2005]. 
Table 2: Parsons/Thompson Model of Organizational Structure ${ }^{8}$

\begin{tabular}{l|l|l} 
Level & Purpose & Activities \\
\hline Organizational/Executive & $\begin{array}{l}\text { Establish rules and relate to larger society, } \\
\text { making possible the implementation of organi- } \\
\text { zational goals. }\end{array}$ & $\begin{array}{l}\text { Interface with the external environ- } \\
\text { ment to determine the organizational } \\
\text { domain and secure legitimacy. }\end{array}$ \\
\hline Managerial & $\begin{array}{l}\text { Mediate between the organization and the task } \\
\text { environment; administer internal affairs; pro- } \\
\text { vide resources. }\end{array}$ & $\begin{array}{l}\text { Provide internal political mediation } \\
\text { between the organizational levels. }\end{array}$ \\
\hline Technical & Create the organizational product. & $\begin{array}{l}\text { Execute production and/or develop- } \\
\text { ment functions; protect the production } \\
\text { functions from external uncertainties. }\end{array}$
\end{tabular}

Becoming more common is the organizational network model, where work is carried out by cooperative networks of local and remote individuals and teams. Teams are functionally based and locally managed, removing layers of organizational management. As a result, the teams are flexible and can change function, goals, or make-up as necessitated by internal or external influences [Bernard 2005].

Gunasekaran and Garets articulate some good criteria for strategic planning participation. A wellformed strategic planning team should include

- $\quad$ executive support and access

- a representative microcosm of the organization, with multiple levels of management

- $\quad$ an external perspective [Gunasekaran 2004]

An empowered representative group is the best faction to conduct strategic planning. But strategic thinking must involve personnel at the highest level of an organization. It is not a low-level project or a delegated task. Without executive input there is insufficient knowledge and authority to do meaningful strategy setting.

8 Adapted from Scott Bernard's 2005 book titled An Introduction to Enterprise Architecture [Bernard 2005]. 
SOFTWARE ENGINEERING INSTITUTE | 8 


\section{Critical Success Factors}

The toughest thing about success is that you've got to keep on being a success.

-Irving Berlin 9

\subsection{Critical Success Factors}

Critical success factors were introduced by John F. Rockart and the MIT Sloan School of Management in 1979 as a way to help senior executives define their information needs for the purpose of managing their organizations [Rockart 1979]. Rockart traced his CSF work to its conceptual antecedent, "success factors," introduced by D. Ronald Daniel in 1961. Daniel had discussed the problem of inadequate management information for setting objectives, shaping strategies, making decisions, and measuring results against goals. Daniel asserted that organizational planning information should focus on "success factors," which he described as "three to six factors that determine success...key jobs [that] must be done exceedingly well for a company to be successful" [Daniel 1961].

Although Rockart did not use CSFs for strategic planning, he noted that the success factor concept was in itself useful for applications other than those he used. Rockart's primary purpose with CSFs was to gather information needs for management decision-making.

\subsection{CSF Characteristics}

It is important to understand the characteristics of CSFs. Some key characteristics are summarized here: CSF hierarchy, types, uniqueness, and stability over time.

\subsubsection{CSF Hierarchy}

In Daniel's work, success factors are described at the industry level, and they are shared across organizations within an industry. Daniel focused on non-unique industry-level success factors (i.e., success factors that are relevant for any company in a particular industry). Anthony et al. expanded Daniel's work by suggesting that CSFs could differ from company to company and from manager to manager, introducing the concepts of managerial-level CSFs and organizationally unique CSFs [Anthony 1972]. Caralli also adopted this perspective.

Levels of management introduce different types of operating environments and thus different levels of CSFs. Bullen and Rockart provide a thorough discussion of the hierarchical nature of CSFs and identify four specific levels of CSFs: industry, organizational, ${ }^{10}$ division, ${ }^{11}$ and individual. Caralli introduces the concept of operational-unit CSFs, which focus on the contributions that

Berlin, Irving. Book of Positive Quotations, second ed. Edited by John Cook, Rubicon Press, Inc., 2007.

10 Rockart refers to these as "corporate" CSFs; Caralli refers to these as "enterprise" CSFs.

1 Rockart refers to these as "sub-organization" CSFs. 
an entity makes to support the organization's overall goals and mission, and supports the concept of operational units in the IT strategy context. Caralli also draws an explicit parallel between CSF hierarchy and planning hierarchy by pointing out the similar way in which both hierarchies are interdependent. He notes, however, that CSFs do not necessarily cascade through the layers of an organization in simple one-to-one relationships [Caralli 2004]. Figure 2 shows the critical success factor hierarchy.

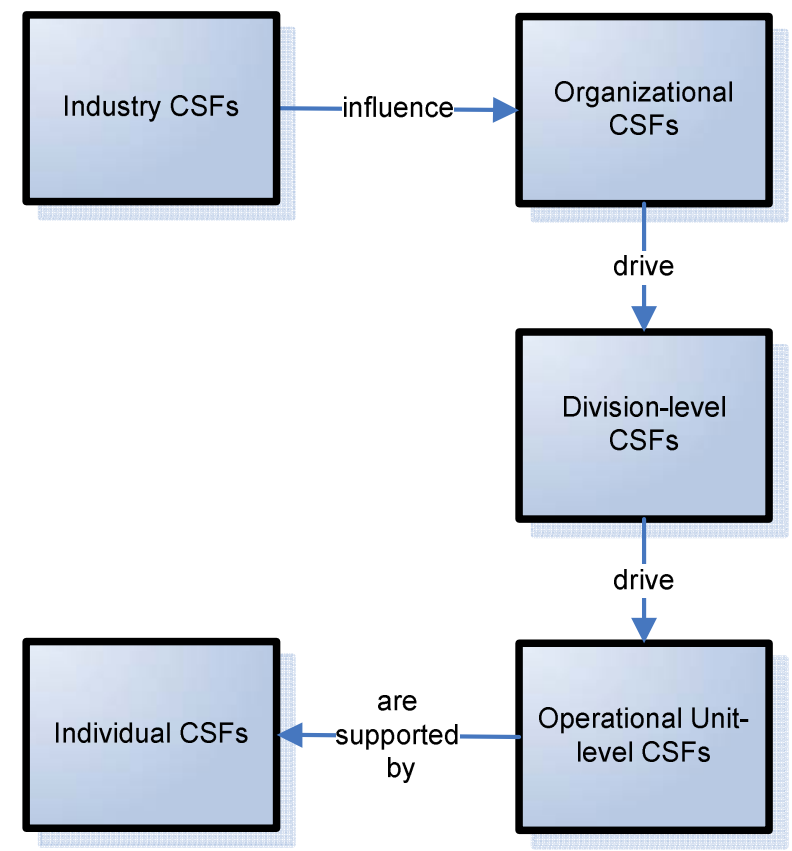

Figure 2: Critical Success Factor Hierarchy

\subsubsection{CSF Types}

In addition to the types of CSFs introduced by levels of management, Rockart identified five types of CSFs that reflect the way in which they contribute to the achievement of the mission:

- the structure of the particular industry (industry CSFs)

- competitive strategy, industry position, and geographical location (strategy CSFs) ${ }^{12}$

- $\quad$ the macro environment (environmental CSFs) ${ }^{13}$

- $\quad$ problems or challenges to the organization (temporal CSFs) $)^{14}$

- management perspective (management CSFs)

12 Caralli calls these "peer" CSFs.

${ }^{13}$ Future scenarios also explore the macro environment.

14 Temporal CSFs can also be viewed as indicators of performance gaps, and can then be elevated to goals, as noted in section 5.3.2.2, "CSFs and Goals." 
An organization's CSFs may include any or all of these types. Understanding the type of CSF helps an organization know whether the CSFs are shared or unique and how they may persist or evolve over time.

\subsubsection{CSF Uniqueness}

Caralli puts significant focus on understanding the CSFs that are unique to an industry, organization, or manager. But CSFs are not necessarily unique to the organization, division, operational unit, or individual to whom they apply. Rockart focused on the CSFs at the managerial level, along with department- or organizational-level CSFs (though he continued to acknowledge industry-level CSFs). He also noted that CSFs could be non-unique (shared across the industry) or uniquely linked to internal and external sources other than the industry.

\subsubsection{CSF Stability Over Time}

Although CSFs may remain fairly constant over time, at least in the sense of a strategic planning period, from Rockart and Bullen's perspective, CSFs change "as the industry's environment changes, as the company's position within an industry changes, or as particular problems or opportunities arise" [Bullen 1981]. Rockart also points out that CSFs are not key indicatorsstandard measures that can be applied across all divisions of an organization. There can be some migration between CSFs and specific goals, particularly when a CSF reflects a challenge or problem (temporal CSFs). A "performance gap" in a particular operational area may cause a CSF to be elevated into a fix-oriented goal. Alternately, a goal, once achieved, may migrate to a CSF for sustainment.

\subsection{The Critical Success Factor Method}

Rockart introduced a two-phased, interview-based method that began with a discussion of an executive's goals and the underlying CSFs, followed by the development of CSF measures. Caralli offers a five-step method: ${ }^{15}$

- define scope

- collect data

- $\quad$ analyze data

- $\quad$ derive CSFs

- $\quad$ analyze CSFs

This method provides a way of deriving CSFs through a document review and analysis of the goals and objectives of key management personnel, as well as interviews with those individuals about their specific domain and the barriers they encounter in achieving their goals and objectives. The collected information is formed into statements that represent the activities

\footnotetext{
15 In The Critical Success Factor Method: Establishing a Foundation for Enterprise Security Management Caralli provides a detailed CSF method description [Caralli 2004].
} 
that key managers perform; these activities are analyzed and placed into affinity groupings from which the CSFs are derived. 


\section{Future Scenarios}

It is only when you're forbidden to talk about the future that you suddenly realize how much the future normally occupies the present, how much daily life is usually spent making plans and attempting to control the future. Never mind that you have no control over it. The idea of the future is our greatest entertainment, amusement, and time-killer. Take it away and there is only the past...

- Erica Jong ${ }^{16}$

\subsection{Future Scenarios}

Scenarios were first used as a military planning tool in World War II. Herman Kahn helped scenario planning take root in the civil domain shortly after the war. Schwartz defines a scenario as a tool for ordering one's perceptions about alternative future environments in which one's decisions might play out. Scenarios encourage the exploration of multiple "futures" and the perceptive development of decisions or strategies that will serve the uncertain future well [Schwartz 1996, van der Heijden 1996].

Wilkinson provides a good high-level description of scenario planning. He writes: "Scenario planning derives from the observation that, given the impossibility of knowing precisely how the future will play out, a good decision or strategy to adopt is one that plays out well across several possible futures. ... [T] he purpose of scenario planning is not to pinpoint future events but to highlight large-scale forces that push the future in different directions" [Wilkinson 1995].

\subsection{The Future Scenario Method}

Global Business Network, a leader in scenario-based planning, uses a group-exercise approach to scenario work. Van der Heijden describes an interview-based method much like the one described for eliciting CSFs. Ogilvy and Schwartz provide a good description of the scenario-planning method [Ogilvy 2004]. In either case, the basic method for developing future scenarios uses these major steps:

1. Identify a focal issue or major decision the organization faces.

To ensure that the scenarios will be relevant to the organization's business environment, the organization begins by identifying an issue or decision that matters to the organization. In this fashion, the organization conducts the work "from the inside out." A focal issue can be broad (what will characterize our business environment in 10 years?) or more narrow (should we introduce a new product line?).

2. Identify the driving forces in the macro environment that influence the key factors.

16 Jong, Erica. Fear of Flying. Signet, 1973. 
Common areas of consideration are social, economic, political, environmental, and technical forces. Research into areas such as new markets, technology trends, political factors, and economic forces is appropriate. This step can be difficult if the organization is not used to doing anticipatory thinking. Figure 3 provides an example of driving forces for government health care.

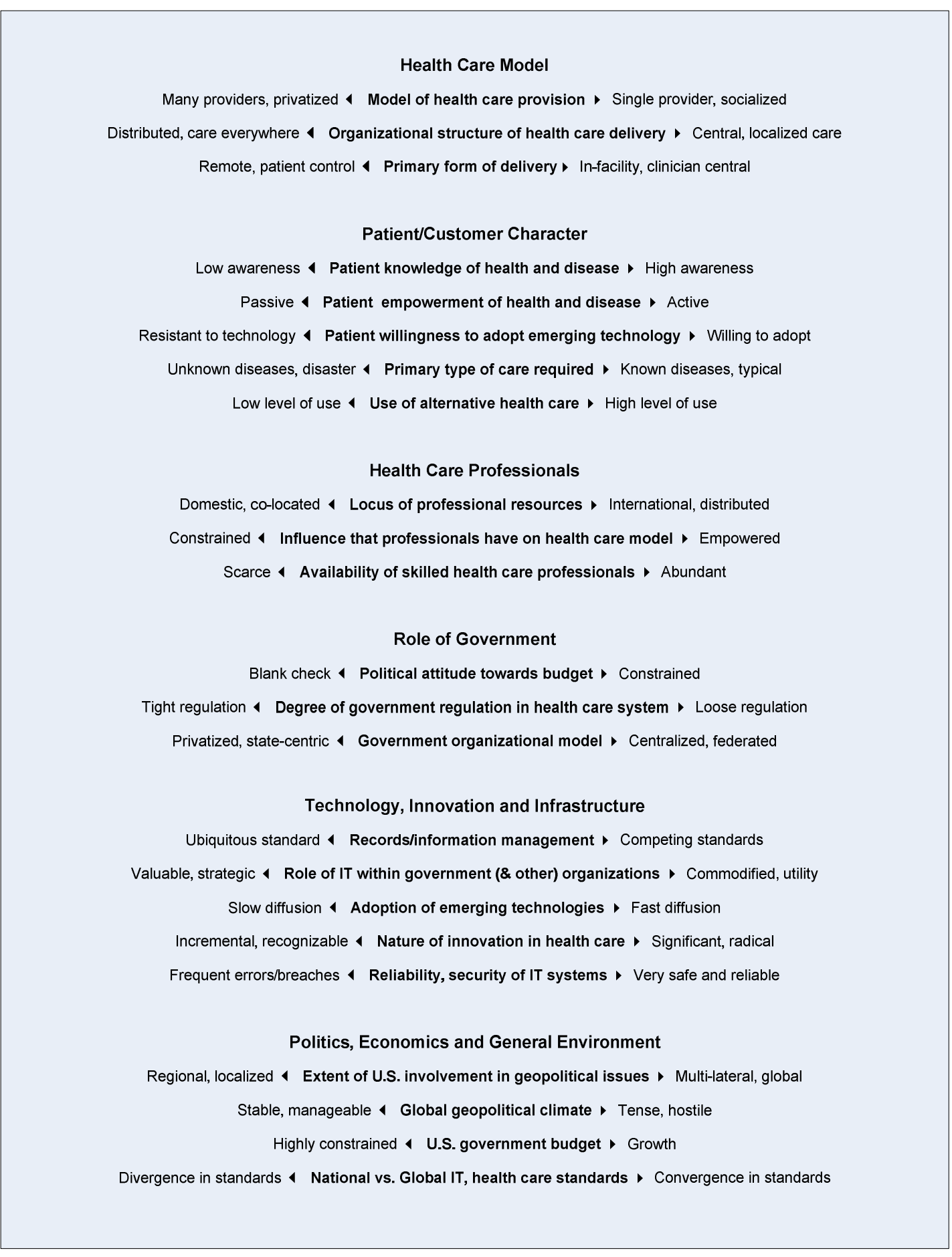

Figure 3: Example Driving Forces for Government Health Care 
3. Identify the critical uncertainties relevant to the focal issue.

The organization ranks each key factor and driving force based on its importance to the focal issue or decision and the degree of uncertainty surrounding it. The goal is to identify the factors and forces that are the most important and the most uncertain. ${ }^{17}$ Figure 4 provides an example of critical uncertainties for government health care.

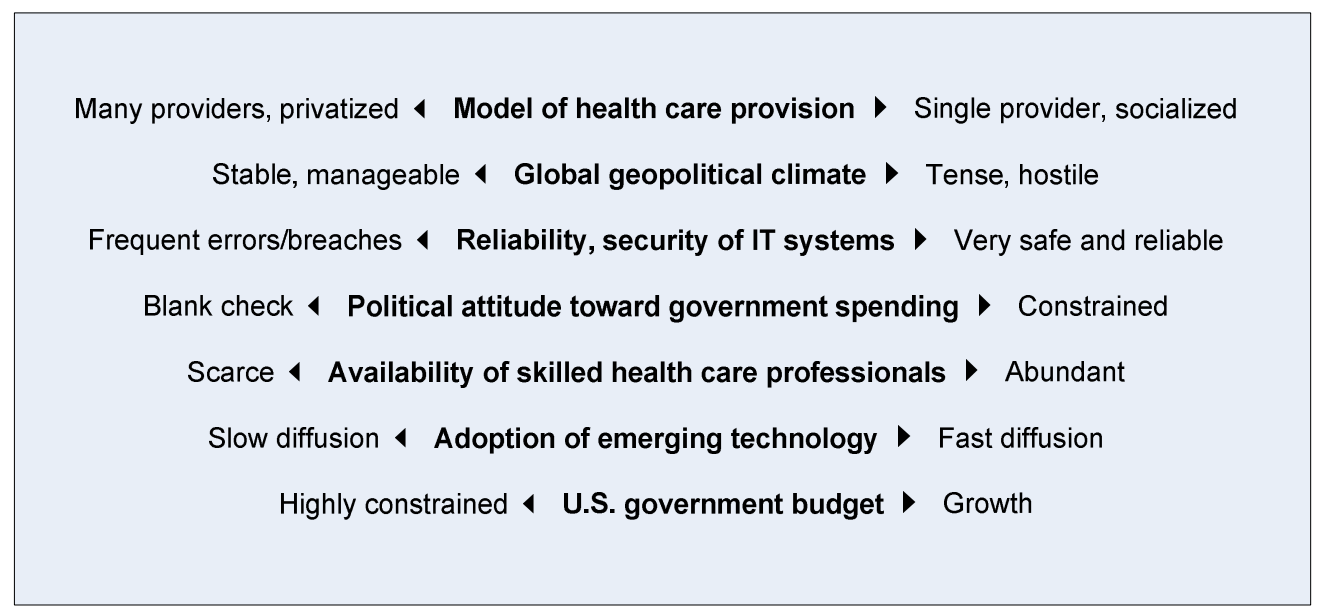

Figure 4: Example Critical Uncertainties for Government Health Care

17 Certain forces might be identified (e.g., the aging of a population) will not be appropriate to investigate as critical uncertainties. These forces should be planned for as inevitabilities. 


\section{Select scenario logics.}

Possible futures are identified by examining critical uncertainties. Critical uncertainties can be examined along a spectrum (a single axis), a matrix (two axes), or a volume (three axes). The goal is to create just a few scenarios whose eventuality will make a difference to decision makers.

Figure 5 shows an example scenario matrix for government healthcare.

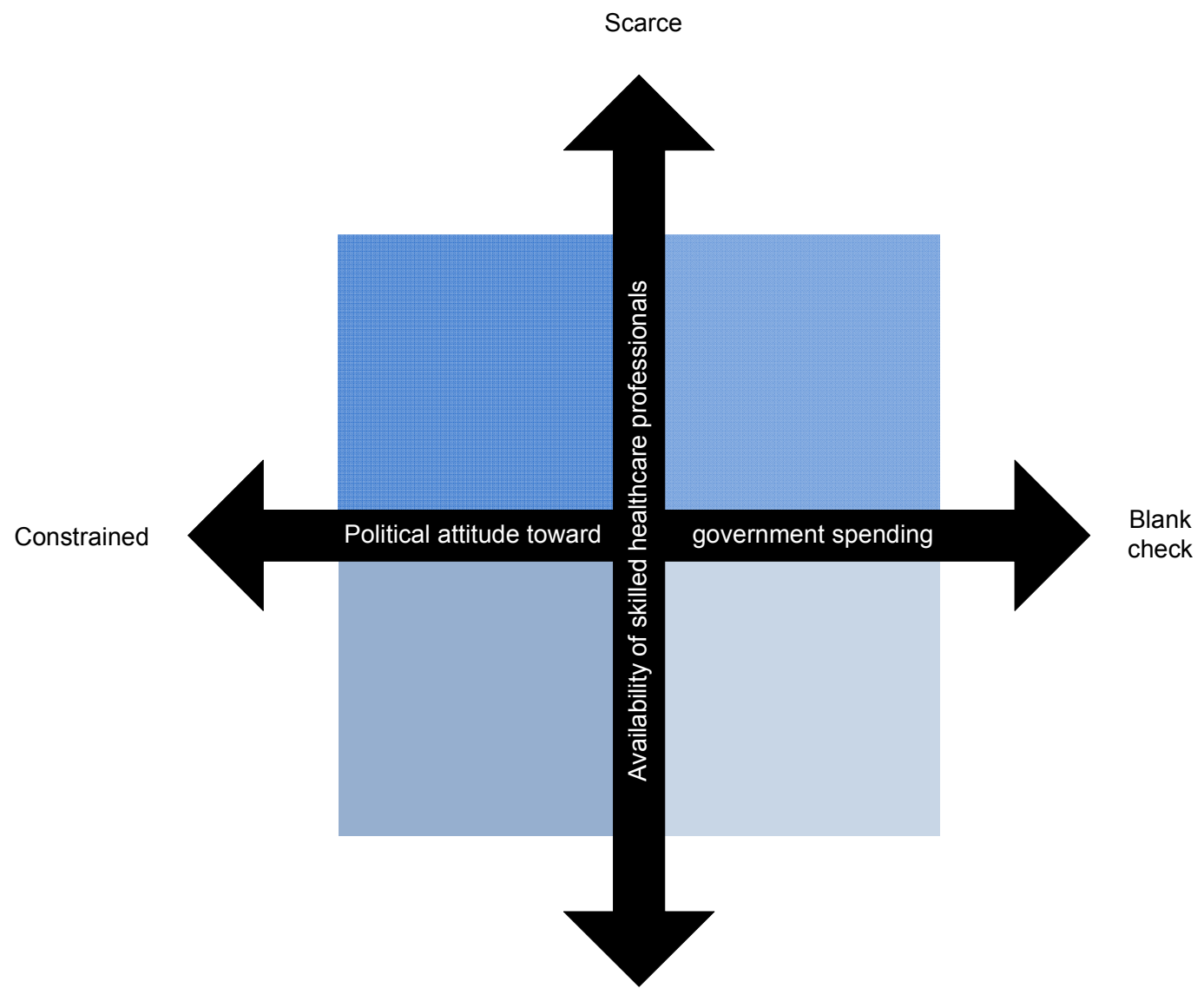

Abundant

Figure 5: Example Government Health Care Scenario Matrix 
5. Flesh out the scenarios.

Each scenario is then expanded into a narrative that addresses the critical uncertainties. The resulting scenarios represent very different, but plausible, futures that are relevant to the focal issue. The goal in fleshing out the scenarios is to describe each future in such a way that its limits are explored and understood. Each narrative should be compelling and thought provoking. Figure 6 provides an example of the types of scenarios generated for government health care. The scenario titles in each quadrant would be supported by a narrative describing government healthcare in the context of variations in the government customer base and government regulation.

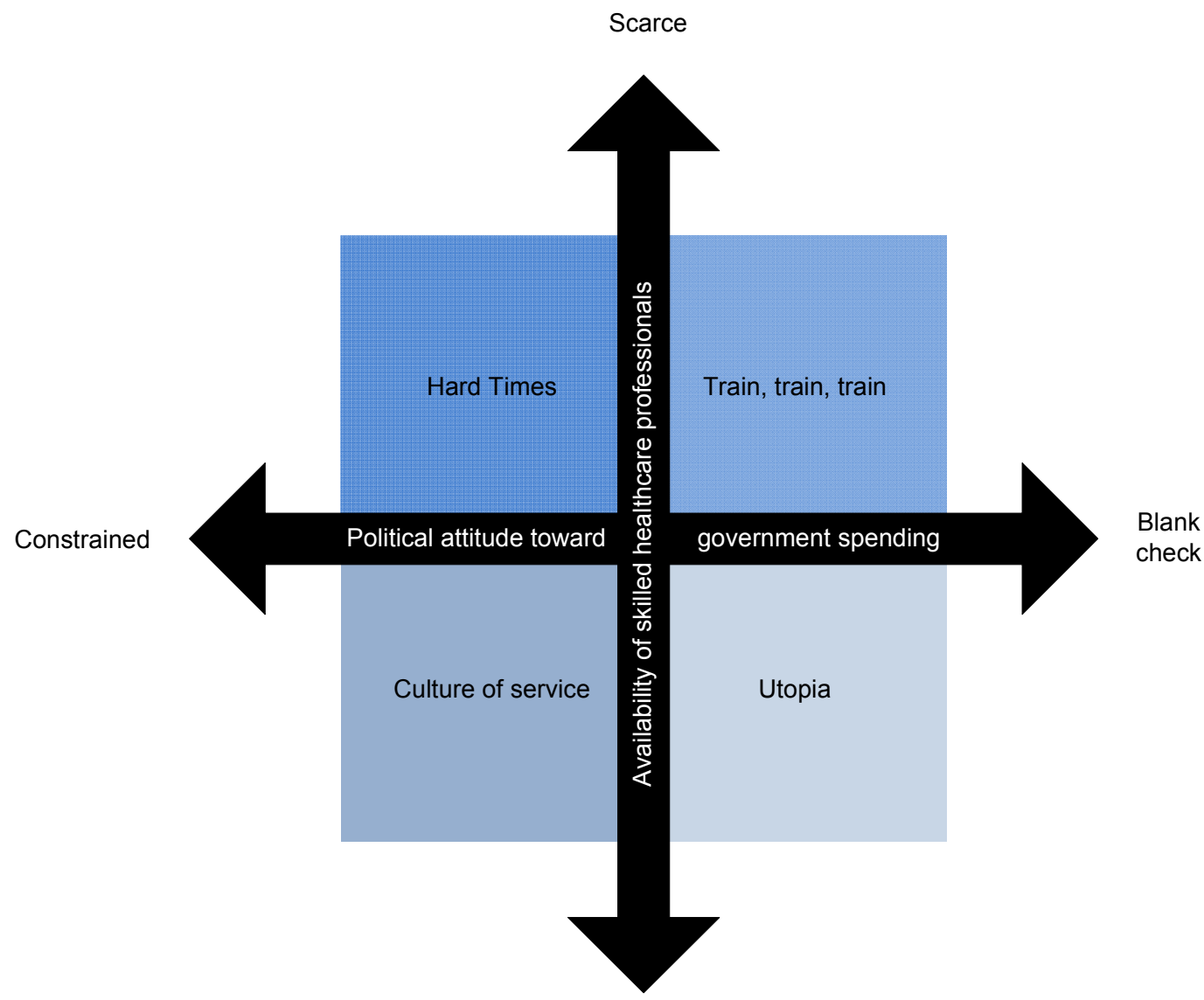

Abundant

Figure 6: Example Government Health Care Scenarios with Narrative Titles 
6. Identify implications and robust strategies.

The organization considers how the focal issue or decision will look across the various scenarios. Which decisions or strategies will work well across multiple scenarios? Strategies that serve well in multiple, varied futures are considered robust. Figure 7 shows scenarios for government health care with possible implications for each scenario.

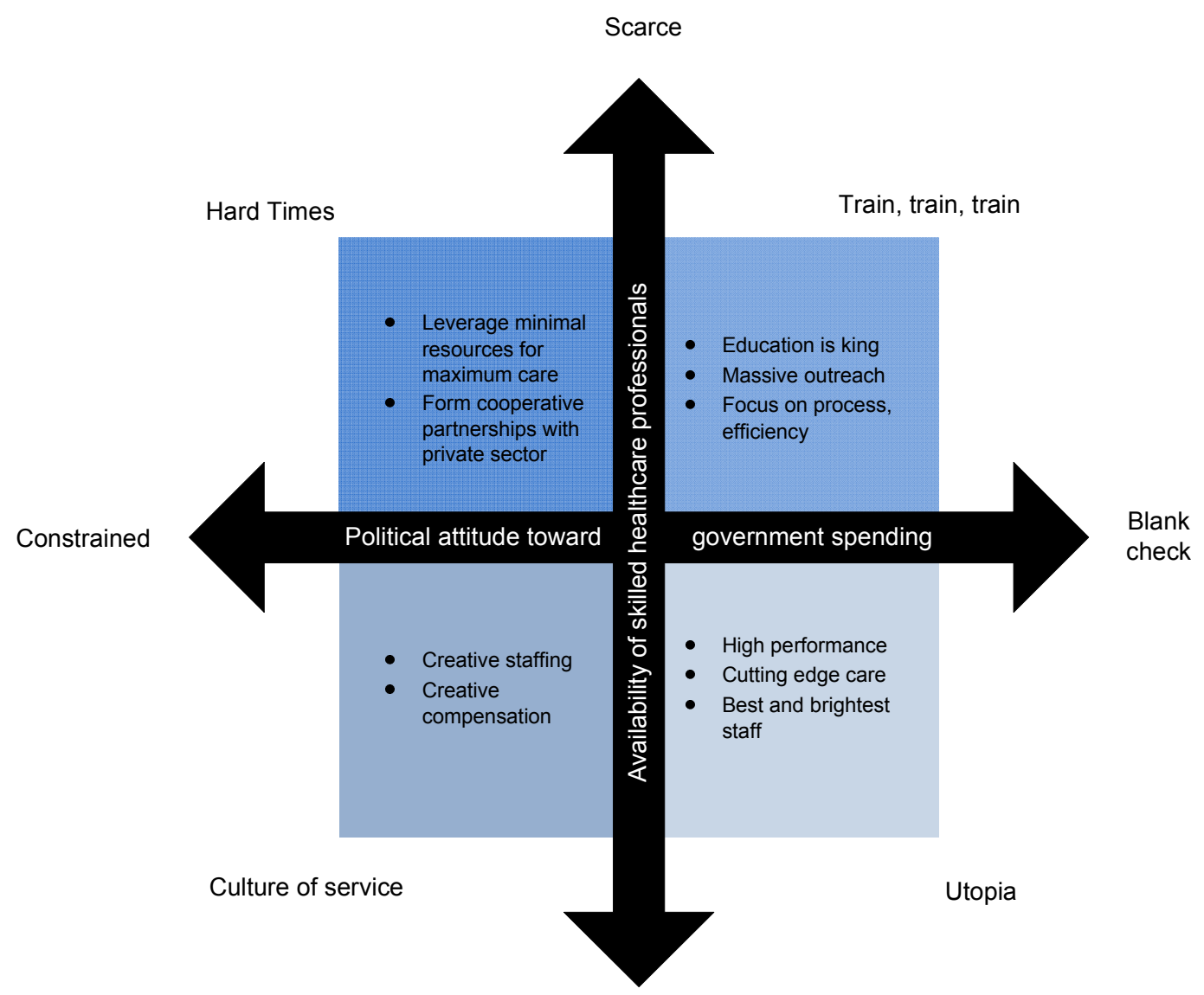

Abundant

Figure 7: Example Government Health Care Scenarios with Implications 


\section{Identify indicators.}

Indicators are early warning signs that a particular scenario is or is not unfolding. Indicators can help an organization understand how the future affects its strategies and decisions. The logical coherence built into a scenario allows the implications of important indicators to be drawn back out of the scenarios; the scenarios can translate the behavior of an indicator into organization- or industry-specific implications.

Once scenario planning is complete, the scenario insights can be used to develop full organizational strategies.

\subsection{General Limitations of Scenario Planning}

John Schoemaker's “Twenty Common Pitfalls in Scenario Planning” highlights common difficulties with scenario planning. He divides the issues into two categories: process pitfalls and content pitfalls. Process pitfalls are those having to do with how the exercise was conducted. Content pitfalls are those having to do with the scenario material itself. The article underscores the need to use scenario planning carefully and wisely [Schoemaker 1998].

One of the pitfalls Schoemaker describes is the failure to link scenarios into the planning process. He writes, "The scenario process should not be an isolated activity, unconnected to other organizational decision-making processes. Ideally, scenario planning should be tied into the existing planning and budgeting process. However, the transition from using scenarios as thinking frameworks and intellectual lenses to using them for project evaluation requires careful management."

M. Conway underscores the importance of viewing scenarios as a trigger for continuing conversations about the future and illuminating previously unconsidered options [Conway 2004].

Scenarios are very useful tools for exploring the future. Their full potential arrives through the application of the scenarios to a decision-making process. 


\title{
5 Integrating Critical Success Factors and Future Scenarios with Strategic Planning
}

\author{
It all comes down to the ability to go up and down the ladder of abstraction, and being \\ able to see both the big picture and the operational implications.
}

-Loizos Heracleous ${ }^{18}$

\subsection{Strategic Thinking}

A common criticism of strategic planning is that it is overly involved with extrapolation of the past and present and can create the illusion of certainty regarding the future [Heracleous 1998]. A good strategic planning process does more than produce a tangible output (a documented plan); it supports ongoing strategic thinking, discussion, and behavior. In a good strategic process the strategic plan provides a dynamic map for an organization's considered movement through time and sets the stage for enterprise architecture and organizational improvement efforts.

Strategic thinking focuses on finding and developing organizational opportunities and creating dialogue about the organization's direction. Strategic thinking is creative, divergent, and synthetic while strategic planning is conventional, convergent, and analytical [Liedtka 1998]. When strategic thinking is employed, the planning process itself provides critical value — but strategic planning is still required for effective strategic work. If nothing else, the divergent results of strategic thinking must be made operational through convergent strategic planning.

Jeanne Liedtka provides a thoughtful analysis of the essential differences between traditional strategic planning and strategic thinking. She explains that strategic thinking involves five elements: a systems perspective, a focus on intention, a focus on time, a focus on opportunity, and hypothesis testing. She presents a framework for creating a strategic process that continually examines the tension between aligning to a plan and fostering change and adaptability [Liedtka 1998]. Conway presents a framework that links strategic thinking to the articulation of options, and strategic planning to the generation of actions [Conway 2004]. Figure 8 shows a high-level strategic planning process that allows a balance between strategic thinking and strategic planning.

18 Heracleous, Loizos. "Strategic Thinking or Strategic Planning." Long Range Planning 31 (1998): 481-87. 


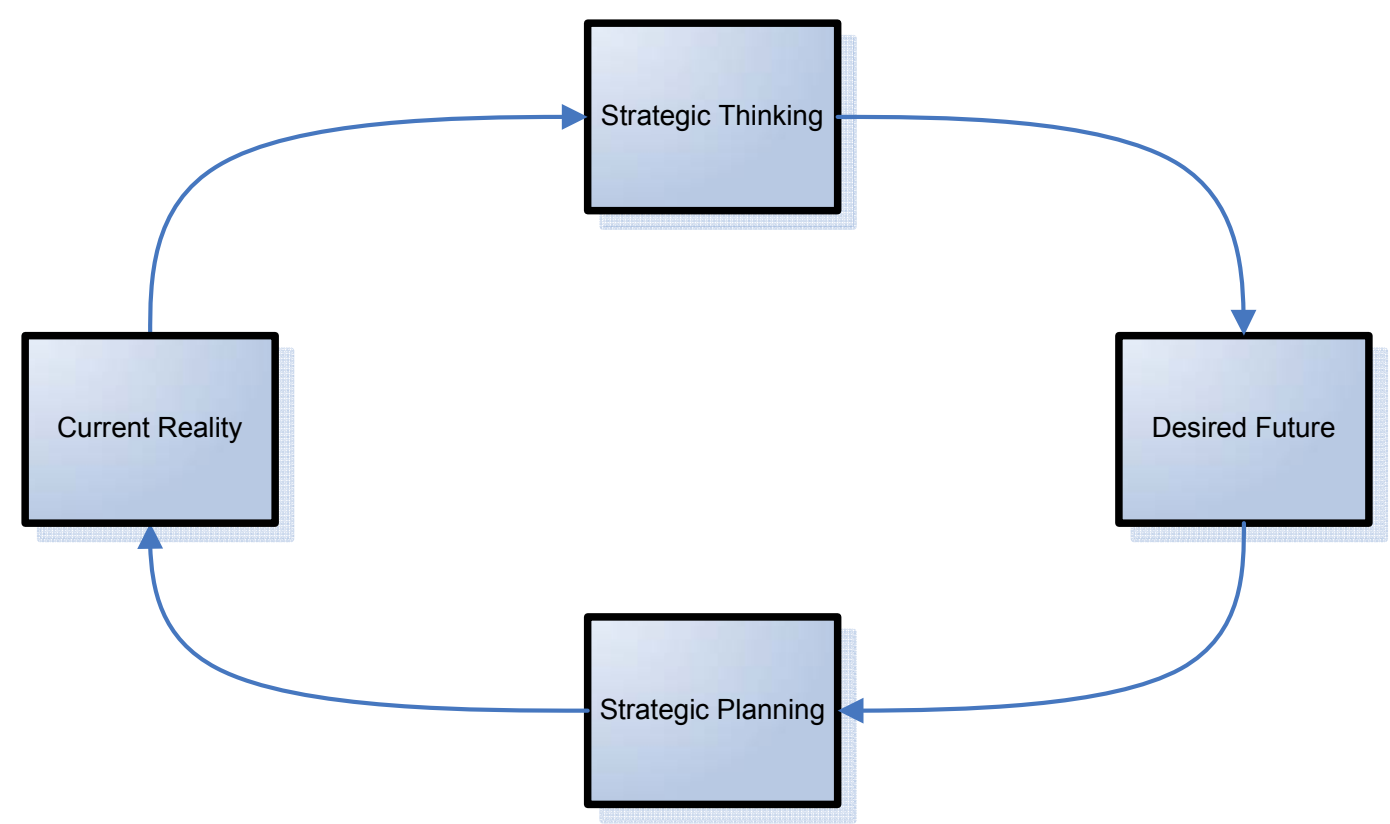

Figure 8: The Strategic Process: Strategic Planning and Strategic Thinking

CSFs and scenarios are stand-alone methods that support strategic planning and strategic thinking. Rockart established the CSF method as a way of identifying the information needs of organizational decision-makers [Rockart 1979]. Van der Heijden identifies the ultimate purpose of scenario planning as helping an organization find a good and unique fit with its ever-changing environment [van der Heijden 1996]. Schoemaker makes a very useful distinction between learning scenarios, those that serve as tentative hypotheses to be explored and tested through discussion and research, and decision scenarios, those that are to be tested against to determine which strategies will serve well in various futures [Schoemaker 1998]. The distinction between learning scenarios and decision scenarios pairs well with the concepts of strategic thinking and strategic planning as discussed by Liedtka.

Both the scenario planning method and the CSF method support strategic decision-making by strengthening the ability to make good, information-based decisions. Expanding the breadth and depth of knowledge and thought that are available for making strategic decisions can only strengthen the decisions and strategies themselves.

\subsection{The Strategy Paradox}

The strategy paradox is a consequence of the conflict between operational commitment and strategic uncertainty. In The Strategy Paradox, Michael E. Raynor provides this definition of the strategy paradox: "The strategy paradox arises from the need to commit in the face of unavoidable uncertainty. The solution to the paradox is to separate the management of commitments from the management of uncertainty. Since uncertainty increases with the time horizon under consideration, the basis for the allocation of decision making is the time horizon for which different levels of the hierarchy are responsible: the corporate office, responsible for the longest item horizon, must focus on managing uncertainty, while operating managers must focus on delivering on commitments" [Raynor 2007]. 
Raynor recommends separating the work of delivering on organizational commitments (operational activities) from mitigating the risks associated with future uncertainty while providing exposure to promising opportunities (strategy setting). He goes on to propose that each organizational level be defined by its relationship to managing strategic uncertainty. He tasks executives with strategic planning, scenario planning, and managing uncertainty, and managers with operational planning, critical success factors, and product or service delivery. He even asserts that an organization must often accept mediocrity (or lack of huge success) as the price of existence to allow for the pursuit of great success.

Michael E. Porter differentiates operational effectiveness from strategic positioning by highlighting that operational effectiveness is akin to efficiency, and means performing similar activities better than one's industry peers. Strategic positioning means adopting activities that are different from one's peers, or performing similar activities differently [Porter 1996].

\subsection{Integrating Critical Success Factors and Future Scenarios with Strategic Planning}

CSFs and scenarios each augment important pieces of the typical strategic planning landscape.

CSFs articulate operational activities that support the mission and reveal information to be monitored over time. Scenarios lead to strategic conversations and uncover potential futures for which an organization can monitor. CSFs and scenarios, although they produce tangible results, also provide processes that help an organization establish strong ways of thinking, communicating, and making decisions. ${ }^{19}$ Figure 9 shows the schematic way in which CSFs and scenarios integrate with the typical strategic plan elements.

19 Van der Heijden casts strategy development as a "learning loop" in which perception, thinking, and action are fundamental, non-static parts [van der Heijden 1996]. 


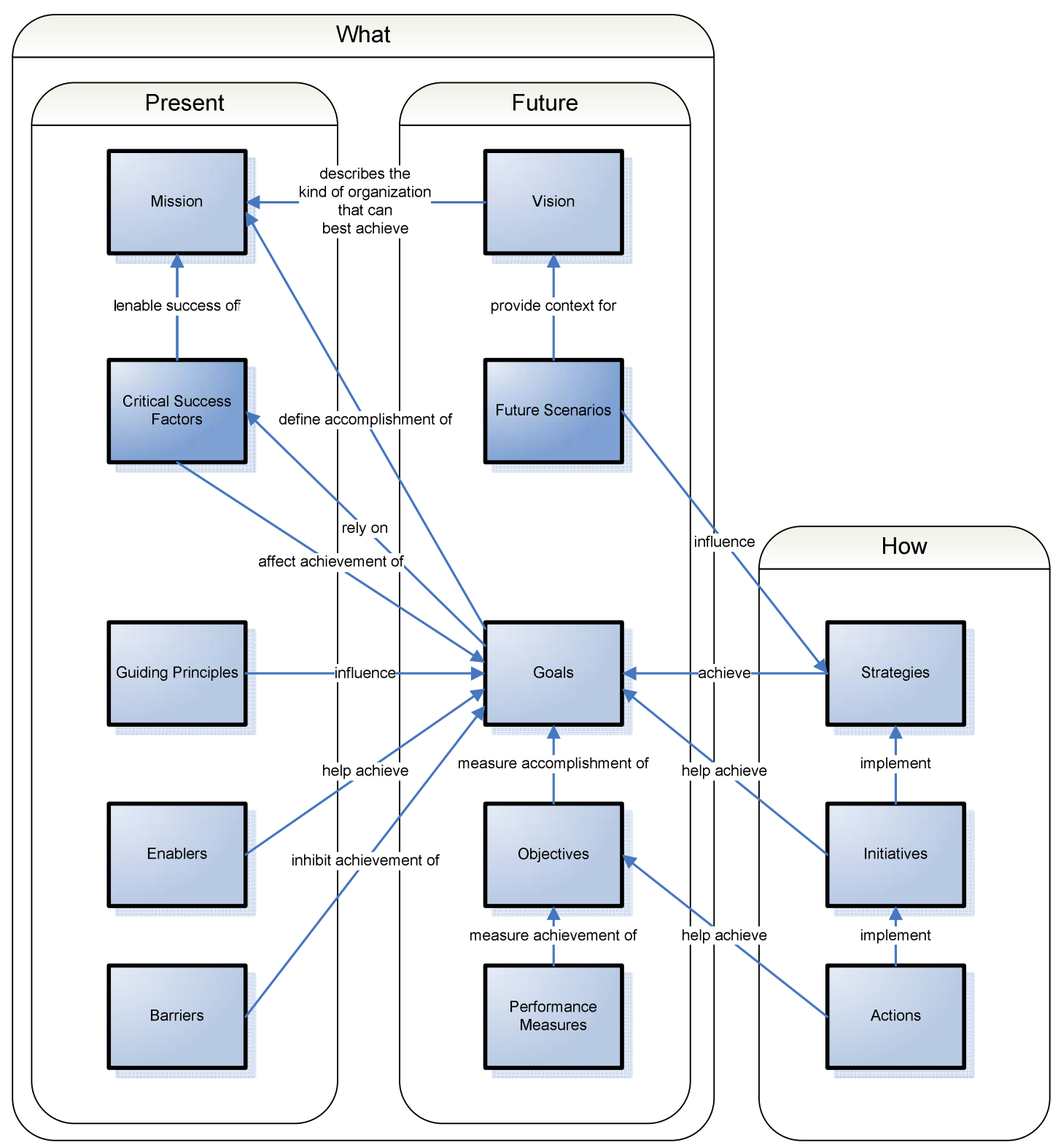

Figure 9: Critical Success Factors and Future Scenarios with Typical Strategic Planning Elements

Implementation of a strategic plan, coupled with review and maintenance of the strategy to ensure that it stays relevant over time, are critical components of strategic planning not covered in this paper. Both the critical success factor method and the scenario planning method stress the importance of maintenance and provide fitting maintenance techniques.

\subsubsection{Critical Success Factors and Strategic Planning}

For Bullen and Rockart, CSFs are made explicit for the purpose of setting priorities and allocating resources, especially management attention. They state that CSFs add value to the planning process by exposing those variables that will most affect success or failure in pursuit of organizational or managerial goals. CSFs describe the operational necessities of the present state. Industry CSFs are "a logical and necessary input into the corporate strategic planning process" and lower- 
level (managerial) CSFs provide useful insight into appropriate resource allocation, or operational planning [Bullen 1981]. Logic would dictate that organizational-level CSFs, which Rockart did not explore, also provide a necessary input into the strategic planning process. Rockart wrote in 1979, "Let me stress that the CSF approach does not attempt to deal with information needs for strategic planning." Bullen and Rockart, however, acknowledged that high-level CSFs are a necessary input to the strategic planning process and that "for an organization to be successful, its strategy must be developed to allow it to excel in those areas where high performance is critical" [Bullen 1981].

Building on Daniel's early work, Robert N. Anthony et al. framed CSFs as "aspects of the business" that were emphasized by management in the hope of gaining a competitive advantage [Anthony 1972]. Caralli emphasized that CSFs contribute toward the accomplishment of a mission and argued that when CSFs are included in the assessment of an organization's current environment, crucial operational elements that enable the success of the mission are more likely to be acknowledged in the resulting strategy [Caralli 2004]. In each case, CSFs can be viewed as a data filter that facilitates strategic or managerial decision-making.

Caralli writes, "Critical success factors (CSFs) define key areas of performance that are essential for the organization to accomplish its mission. Managers implicitly know and consider these key areas when they set goals and as they direct operational activities and tasks that are important to achieving goals. However, when these key areas of performance are made explicit, they provide a common point of reference for the entire organization. Thus, any activity or initiative that the organization undertakes must ensure consistently high performance in these key areas; otherwise, the organization may not be able to achieve its goals and consequently may fail to accomplish its mission" [Caralli 2004].

Bullen and Rockart assert that for an organization to be successful, its strategy must be developed to excel in those areas where high performance is critical, and CSFs are a logical input to the strategic planning process. (In fact, they assert that CSFs are a necessary input to the strategicplanning process.) But CSFs do not provide sufficient input to strategy development. The CSF method must be integrated with a fully defined strategic-planning method that includes a situation analysis component, a visioning component, and a goal-setting component. CSFs fit naturally with planning because they allow an organization to define - at any point in time - the factors that are crucial to the organization's success during the planning period.

Andrew C. Boynton and Robert W. Zmud assert that CSFs are useful in both operational and strategic planning, where they "form a bridge between corporate strategic interests and the strategic planning of the information function.". They go on to say that "CSFs provide a means of explicitly relating information resources to an organization's strategic planning efforts" [Boynton 1984]. 
In their brief discussion of CSFs and strategic planning, Bullen and Rockart link the four levels of CSFs to three levels of planning:

- $\quad$ industry CSFs to strategic planning

- $\quad$ organizational- and division-level CSFs to program planning ${ }^{20}$

- $\quad$ individual CSFs to action planning ${ }^{21}$

In practice, particularly in today's environments, there is cross-wise relevance between the various levels of CSFs and the various levels of planning. With the addition of division-level and operational-unit-level (e.g., IT or security) strategic plans, along with operational-level CSFs, the use of CSFs in organizational planning gets more complicated than what Rockart described. Still, industry-level CSFs are critical to organizational strategic planning, and level-specific CSFs are similarly critical to the associated level-specific plans. Figure 10 shows the relationships between CSF levels and strategic planning levels.

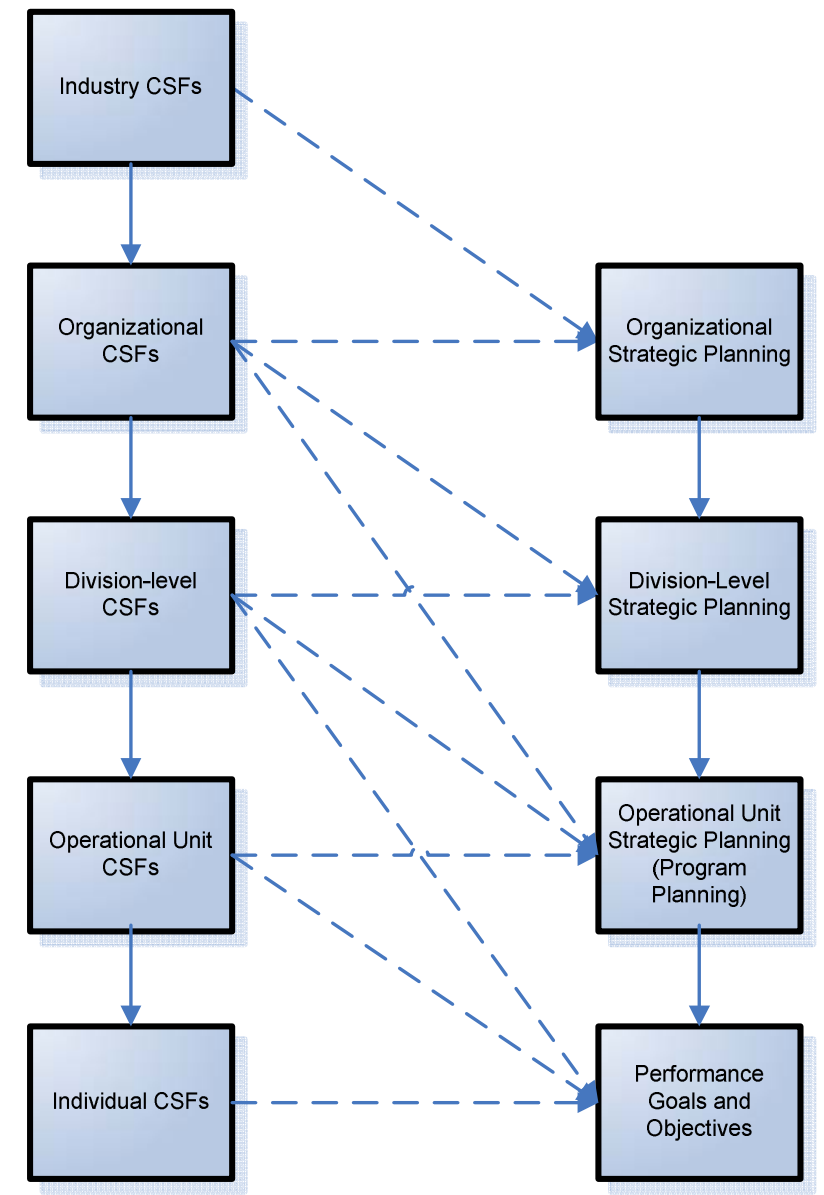

Figure 10: Critical Success Factor Levels and Strategic Planning

\footnotetext{
20 Rockart refers to this as "short-term planning."

${ }^{21}$ Individual CSFs can also be used for setting individual performance goals and objectives.
} 
Caralli argued that deriving CSFs from the highest levels of an organization "tends to bring an acceptable mix of CSFs from many of these sources, so long as a broad cross section of management is represented in the process." He provides detailed recommendations for defining CSF scope (determining the appropriate sources and participants) based on the type of CSFs being developed [Caralli 2004]. ${ }^{22}$

\subsubsection{Critical Success Factors and Typical Strategic Planning Elements}

This section distinguishes CSFs from other strategy elements and clarifies the relationships between CSFs and other elements.

\subsubsection{General Relationships}

CSFs have direct relationships to an organization's mission and goals. Like other strategic planning elements that affect strategy indirectly, CSFs affect strategy through their effect on the organization's achievement of its goals and their ability to enable the success of the mission. Figure 11 shows the relationships between CSFs and strategic planning elements.

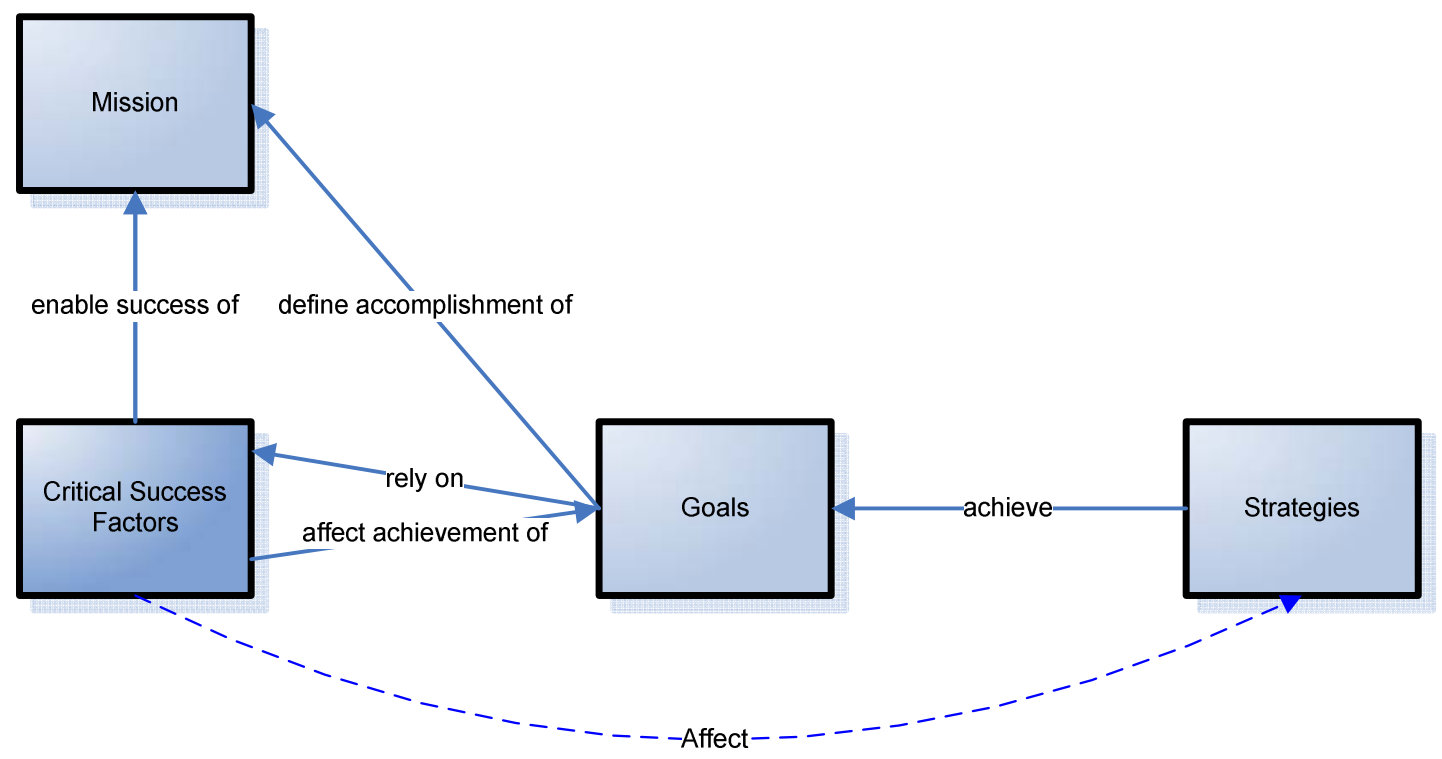

Figure 11: CSF Relationships with Strategic Planning Elements

Anthony et al. link CSFs via information analysis to an organization's ability to capitalize on its own strengths and weaknesses, thereby suggesting a connection between CSFs and current enablers (strengths) and current barriers (weaknesses), similar to the link between goals and enablers/barriers [Anthony 1972]. CSFs also provide an important engine for performance goals.

22 For more information, see Appendix A of Caralli's 2004 SEI technical report The Critical Success Factor Method: Establishing a Foundation for Enterprise Security Management [Caralli 2004]. 


\subsubsection{CSFs and Goals}

There can be some confusion between CSFs and goals, which are not the same. Goals are broad, high-level aims that support the accomplishment of the mission. Like goals, CSFs represent things that enable the success of or contribute to the accomplishment of a mission. Goals, however, are often derived from performance management exercises rather than strategic planning, and are set with an eye to achievability rather than organizational success or contribution to accomplishment of the mission. CSFs refer to ongoing operational activities that must be sustained for the organization to function successfully. Where goals help an organization attain success, CSFs ensure an organization's survival. If an organization focuses only on goal-setting, it might, as a result, drop attention from the day-to-day activities that sustain its success.

Goals and CSFs share a many-to-many relationship because organizational goals may rely on the achievement of more than one CSF and a CSF may affect the achievement of several goals. The potential many-to-many relationship between CSFs and goals is indicative of their interdependence and importance for accomplishing a mission [Caralli 2004]. CSFs reflect areas that are important to the organization in the current operating environment and to future success; they remain fairly constant over time, at least in the sense that they are seen as areas critical to the success of the mission in both the present and the future. Rockart writes, "Goals represent the end points that an organization hopes to reach. Critical success factors, however, are the areas in which good performance is necessary to ensure attainment of those goals" [Rockart 1979].

There is some fluidity among CSFs and goals. As stated earlier, a performance gap in a particular operational area may cause a CSF to be elevated into a fix-oriented goal. Alternately, a goal, once achieved, may migrate to a CSF for sustainment.

\subsubsection{CSFs and Measures}

In an early contribution to the work on critical success factors and management control systems Anthony et al. emphasized that the development of timely, concise measurements was crucial to monitoring identified CSFs [Anthony 1972]. Although not all documented CSF method descriptions include developing CSF measures, measures were also a fundamental part of Rockart's original CSF method. Rockart writes, "Critical success factors are areas of activity that should receive constant and careful attention from management. The current status of performance in each area should be continually measured, and that information should be made available" [Rockart 1979]. Critical success factors can establish a set of performance measures that directly link operational issues to the mission.

\subsubsection{Future Scenarios and Strategic Planning}

The future-focused element of most strategic planning approaches is a description of a desired future, or organizational vision. Because external forces shape the future environment in many ways that are beyond the organization's influence, an analysis of multiple futures greatly increases the value of future analysis. When scenario planning is used, future scenarios describe multiple and plausible futures subject to external forces. 
Future scenarios are inherently linked to planning and decision-making, but their role in setting strategy is not elementary. Scenarios facilitate the identification of large-scale uncertainties or forces that push the future in different directions. A robust strategy is one that will play out well across several possible futures. Strategies that make sense in only one or a small number of precise futures represent a gamble. These can still be pursued, but it will then behoove an organization to look actively for early warning signs that indicate whether a particular future is or is not unfolding [Wilkinson 2004]. Although scenarios can help an organization generate strategic options, both Schwartz and van der Heijden point out that the ultimate product of scenarios is strategic conversation. They also assert that there is no definitive method for selecting a successful strategy [Schwartz 1996, van der Heijden 1996]. ${ }^{23}$

In addition to supporting strategic decision-making, scenarios provide good context for developing an organizational vision, which articulates ways in which the organizational mission might be achieved. While multiple scenarios are explored and maintained, the visioning process ultimately yields a single shared vision. Figure 12 shows the relationships between future scenarios and strategic planning elements.

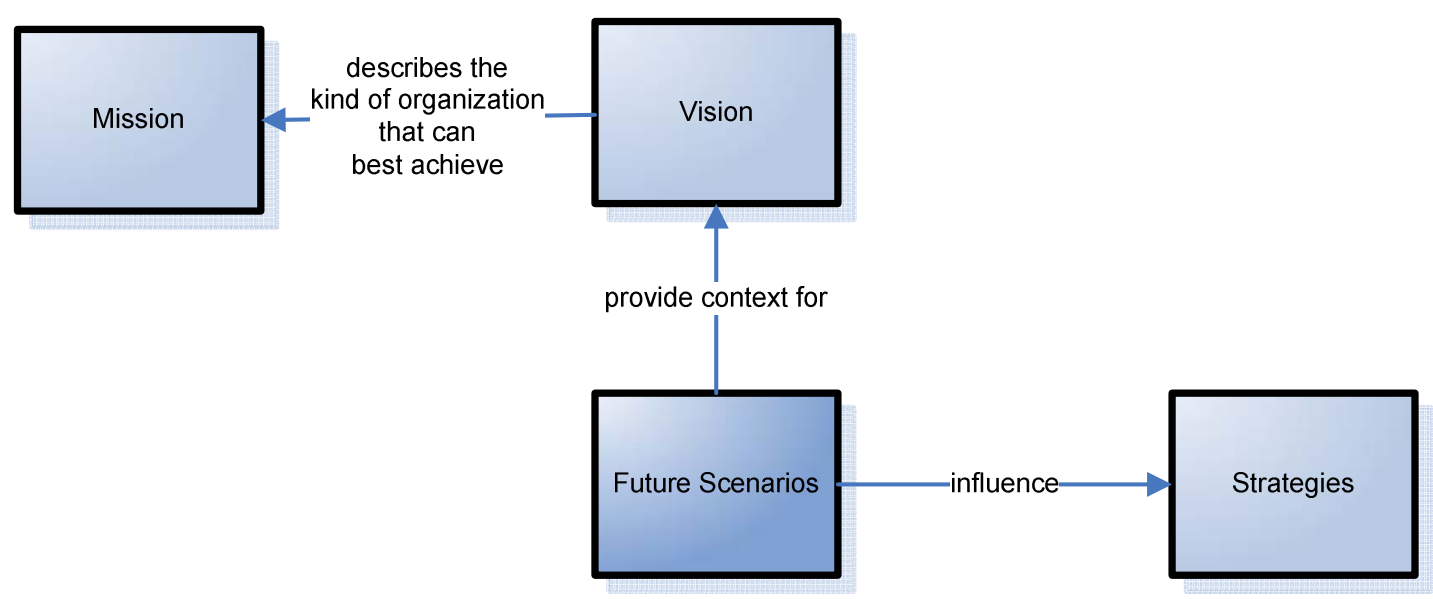

Figure 12: Future Scenario Relationships with Other Strategic Planning Elements

Conway recognizes that a missing element in strategic planning is a systemic view of the future, or what he calls a foresight capacity. Conway concludes that organizations that embrace strategic foresight will have successful strategies, while a lack of foresight will be identified as a contributor to organizational failure [Conway 2004].

Scenario planning is a technique suited for executives at the highest level of an organization. Senior executives are best equipped for long-range planning and managing uncertainty. Along those lines, future scenarios can seed risk-management efforts by highlighting the negative effects of uncertainty. They can act as the opportunistic counterpart to enterprise risk management. The warning signs identified in a future scenario effort might also be used to inform risk management efforts. The SEI has not yet explored these areas.

${ }^{23}$ See Section 7.2, Limitations. 


\subsection{Linking CSFs and Scenarios}

While there is no critical dependency between CSFs and future scenarios, the former can be useful when formulating the latter. CSFs can provide an organizationally tailored filter for highlighting certain scenario drivers. Even Bullen and Rockart link environmental CSFs to future trends, noting economic and political forces in particular - two common categories from which scenario drivers emerge [Bullen 1981].

Daniel, the initiator of the CSF concept, wrote extensively about the need to track environmental information. He writes, "[E]nvironmental data are an aspect of planning information that requires more attention and warrants formalization." Daniel could have been describing several aspects of the scenario data set, from driving forces to early warning signs. Boynton and Zmud found that CSFs can "form a bridge between corporate strategic interests and the strategic planning efforts of the information functions" [Boynton 1984].

In one engagement with a major federal government agency, the SEI used CSFs to expand the characterization of situational drivers. We found that organizational CSFs had particular relevance to economic and political issues (or drivers), and IT CSFs were generally focused on technological issues. Depending on the nature of an organization's business or planning scope, there could be other relationships between CSFs and scenario drivers worth exploring. 


\title{
6 Special Considerations for IT Strategy
}

\begin{abstract}
Information technology and business are becoming inextricably interwoven. I don't think anybody can talk meaningfully about one without talking about the other.
\end{abstract}

-Bill Gates ${ }^{24}$

\subsection{IT Strategic Planning}

In his book An Introduction to Enterprise Architecture, Scott Bernard identifies IT as a commodity - a resource for organizational and mission-specific requirements [Bernard 2005]. In addition to being viewed as a resource for an organization, IT is commonly viewed as an enabler of the non-functional requirements, or quality attributes, of a system (e.g., reliability, availability, usability). IT provides an integral support function to an organization, contributing directly to the efficient and effective achievement of the organizational mission [Caralli 2004]. Before IT, information systems (IS) existed without technological support. Although IT is the current enabler of IS, IS is part of a much larger domain of information and communication that will continue to evolve in response to technological innovation and societal change. ${ }^{25}$

John Ward and Joe Peppard make a distinction between IS and IT that is relevant to understanding IT strategy. IS represents the information and systems that support the overall strategy of the organization. An IS strategy, then, represents the organizational information and systems demand. IT, on the other hand, represents the technology that supports the information needs, or technology supply. Note that IS demands can be met by means other than IT (i.e., by human processes or other non-technical solutions). An IT strategy outlines how technologies will support the organization's information demand and overall business strategy [Ward 2002].

IT strategy refers to a global level of thinking about IT and its integration with the rest of an organization. Enterprise architecture concepts focus on the importance of aligning IT strategies to both cross-cutting (organization-wide) and mission-specific requirements. The ultimate goal of IT strategic planning, according to Gunasekaran and Garets, is to provide a broad and stable vision of how IT contributes to the long-term success of the organization. As with organizational strategic planning, there are documented approaches to IT strategic planning [Cassidy 2006, Bernard 2005, Gunasekaran 2004].

Ward and Peppard point out that in today's environment, an organization's existence depends on the effective application of IT. As a result, organizations increasingly look to technology not only

24 Gates, William H., III. Business @ the Speed of Thought. Warner Books, 1999.

25 This is the underlying factor that allows the early work with management information systems, like CSFs, to translate to an IT application. 
to support business opportunities, but also to create competitive advantage. IT planning has coincidently been elevated from a tactical management tool to a strategic decision-making vehicle. ${ }^{26}$

Figure 13 illustrates the way IT strategy relates to IS needs and organizational and operational unit strategies.

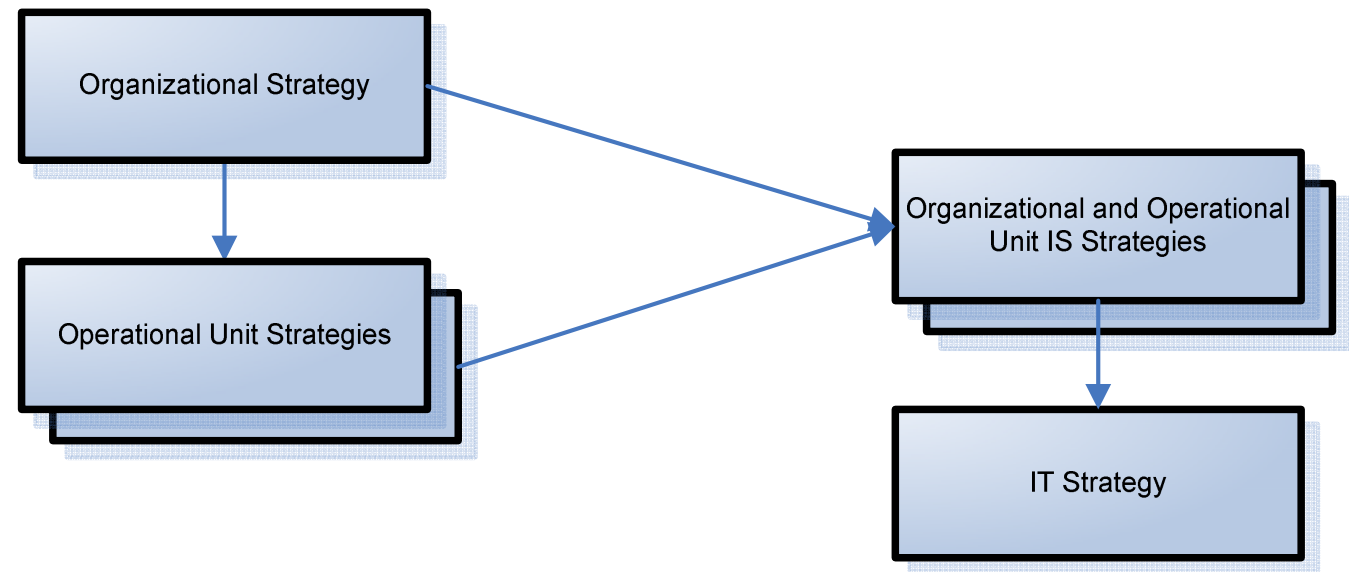

Figure 13: Context for IT Strategy ${ }^{27}$

\subsection{IT Critical Success Factors}

Caralli notes that "operational unit CSFs tend to be less influenced by the organization's industry and more focused on the contributions necessary to support the organization's strategic goals and mission." He points out that the success of an enabling group, or resource, like security or IT, relies heavily on an understanding of higher level CSFs for their own level-specific strategic planning. A good IT strategic plan must include an understanding not only of its own CSFs, but of the CSFs for the divisions of the organization it supports, as well as the higher-level organizational CSFs. In fact, Caralli states that the success for an enabling program can be a reflection of how it contributes to the organization's highest-level CSFs [Caralli 2004].

Caralli has written extensively about using CSFs in a security context. He compared security management challenges to those faced by IT organizations and wrote that organizations have difficulty developing and implementing a security strategy because they do not maintain an explicit focus on business drivers. As a result, security strategies often fail to reflect what is important to the organization, the accomplishment of the mission and long-term resilience. IT organizations face similar struggles with regard to IT strategic planning. Like security organizations, IT organizations often create strategies that fail to answer certain basic questions such as

- What should be supported? What is the priority?

- What kind of support is needed?

${ }^{26}$ Ward and Peppard provide an excellent history of the strategic use of IT in their book Strategic Planning for Information Systems [Ward 2002].

27 Adapted from Strategic Planning for Information Systems [Ward 2002, Figure 3.6]. 
- What happens if the organization is not supported?

- What parts of the organization need to be involved? What if I don't have direct control over them?

- How will success be measured?

Caralli proposes that organizational CSFs can provide answers to these questions because

- They represent the field of vision of top management.

- They reflect the business drivers of the organization.

- They reflect the goals of the organization.

- They provide a unifying effect by articulating a common purpose.

- They can provide a measure for success in demonstrating contribution to the organizational mission [Caralli 2004].

IT organizations tend to function as operational units adjacent to the lines of business, which add value not by producing direct products or revenue, but by enabling or enhancing the way work is accomplished. IT organizations typically address non-functional aspects of organizational plans; they address how work is done - making things faster, more efficient, more reliable, and cheaper. It is important, and difficult, to develop IT strategies that align with organizational goals and directly support the mission. As with organizational strategies, IT strategies can benefit greatly from paying attention to CSFs.

Ward and Peppard talk extensively about the importance of aligning IS/IT investment with the overall objectives and direction of an organization. They refer to the idea of having an IS/IT strategy that makes a contribution to the creation of business value as IS/IT strategic alignment. They propose a strategic alignment model that shows the interdependencies of business strategy, IT strategy, organizational infrastructure and processes, and IS infrastructure and processes [Ward 2002]. Rockart's definition of CSFs as a way to help senior executives define their information needs for the purpose of managing their organizations allows us to view two of these elementsorganizational infrastructure and processes and IS needs - as akin to CSFs [Rockart 1979]. In their assessment of the CSF method, Boynton and Zmud found that CSFs are an excellent tool for IS planning because they induce a structured process for eliciting information needs [Boynton 1984]. ${ }^{28}$ CSFs form a bridge between organizational strategic interests and the informationplanning function. Figure 14 shows how CSFs support IT strategy.

28 It is important to understand that the introduction of CSFs and the cornerstone studies regarding CSFs focus on management information system (MIS) planning and predate the rise of information technology. The application of the CSF technique to strategically-aligned IT is therefore plausible but different from the early work with CSFs. 


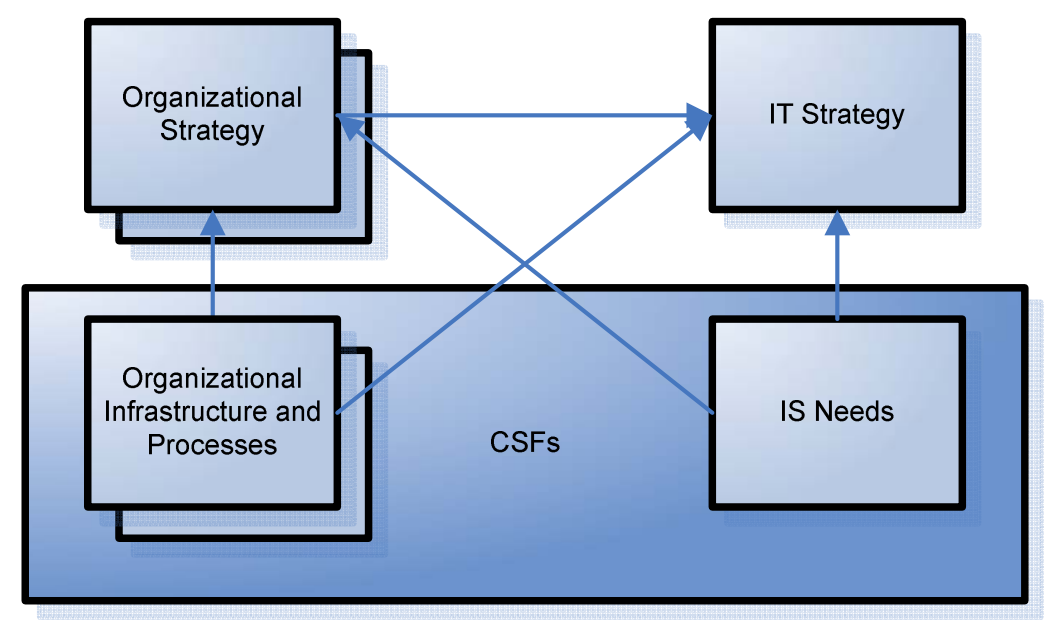

Figure 14: Critical Success Factors and IT Strategy ${ }^{29}$

\subsection{IT Future Scenarios}

The key to an IT strategy is that it explains how information technology will align with and support an organization's overall business strategy and reflects a global level of thinking about IT and its integration with the rest of the organization. For this reason, organizational scenarios can be used to explore IT options. It may also be fruitful to develop IT-specific scenarios, in alignment with organizational scenarios. The SEI has not yet explored this area. Figure 15 illustrates the context for future scenarios in developing IT strategy.

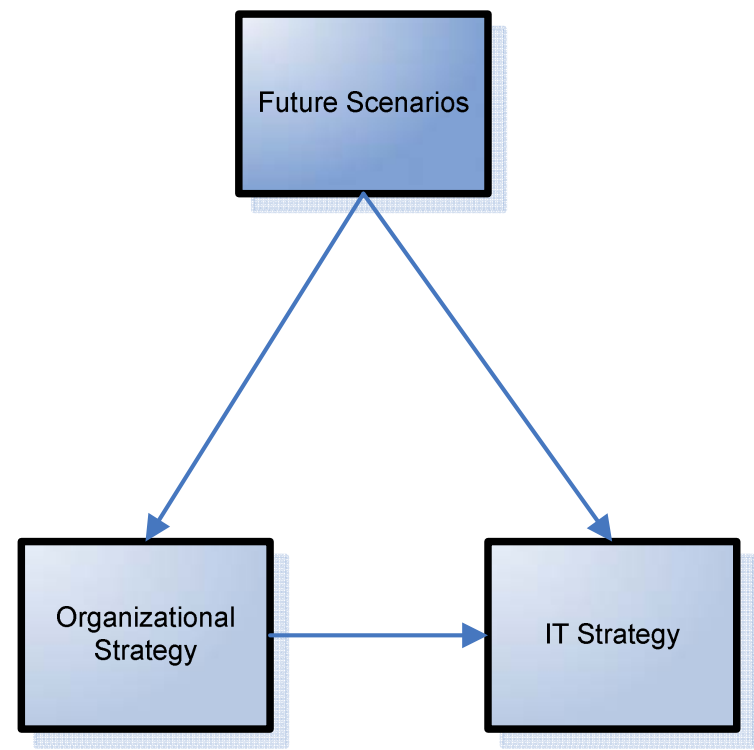

Figure 15: Future Scenarios and IT Strategy ${ }^{30}$

\footnotetext{
29 Adapted from Figure 1.8 in Strategic Planning for Information Systems [Ward 2002].

30 Ibid.
} 


\section{Conclusions}

The trouble with our times is that the future is not what it used to be.

—Paul Valéry, French poet

\subsection{Applicability}

Critical success factors and future scenarios are useful augmentations to strategic-planning efforts. They illuminate an organization's present situation and potential future, respectively, and contribute to a robust strategic planning framework. The enhanced strategic planning framework connects elements of each methodology and improves the depth of strategic analysis and thinking. When the CSF method and scenarios are used together and integrated with a strategic-planning method, they also expose the value of an overarching strategic-thinking and strategy-development process.

The information framework for augmented strategic planning presented in this paper (see Figure 9) serves as an umbrella for enterprise architecture and organizational improvement efforts. A complete set of strategic planning information assets is not hard to build and can stand in for a robust process. Once information assets are developed they can be easily updated and maintained and can open up energy in the organization for improving processes for strategic planning. A fully enhanced strategic planning process, depicted in Figure 16, can be adopted over multiple strategic planning cycles.

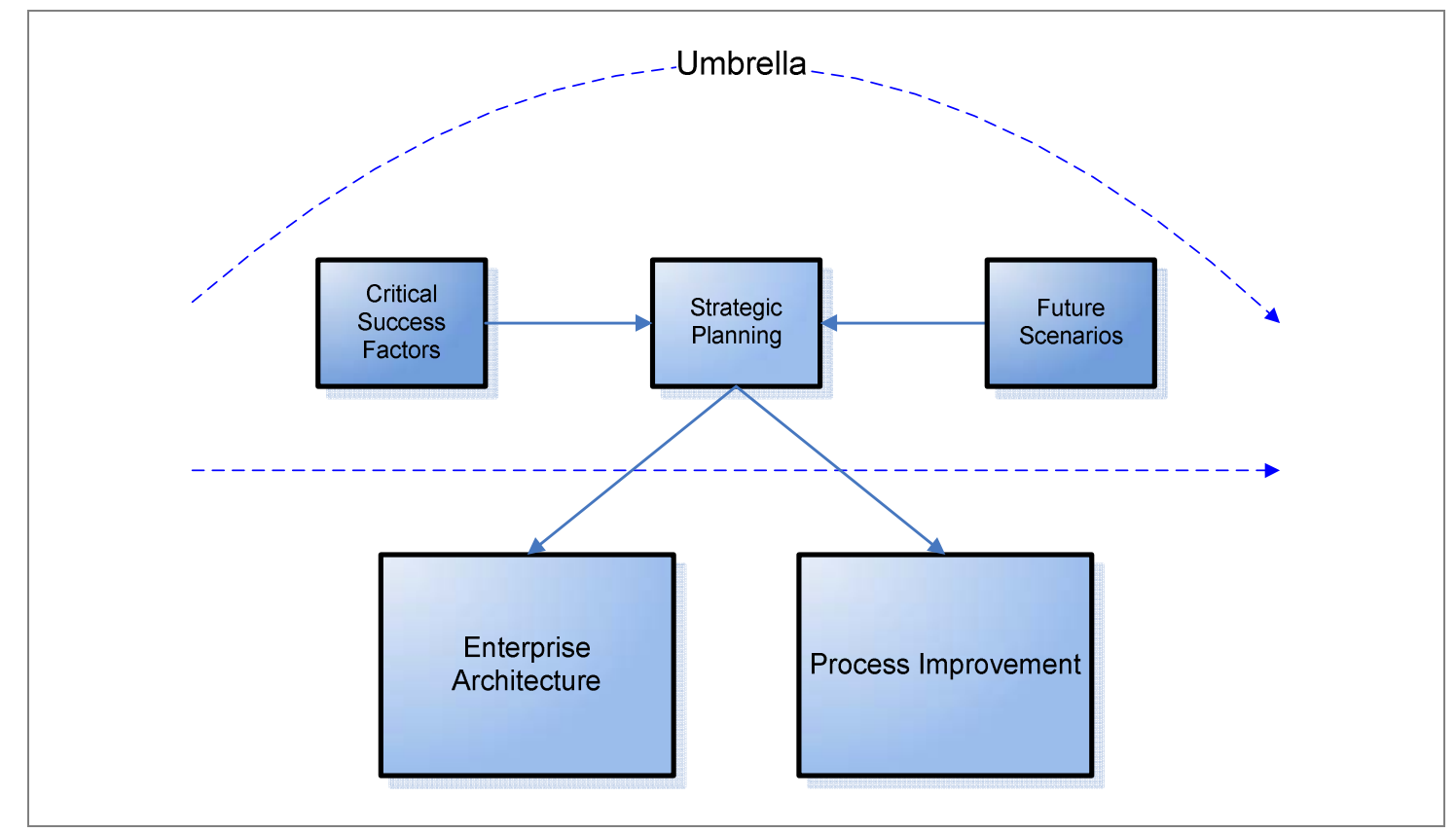

Figure 16: Enhanced Strategic Planning in Context 


\subsection{Limitations}

Strategic planning is best viewed as a way to support strategic decision-making. Rockart established the CSF method as a way of identifying the information needs of organizational decisionmakers [Rockart 1979]. Van der Heijden identified the ultimate purpose of scenario planning as helping an organization find a good and unique fit with its ever-changing environment [van der Heijden 1996]. Both the scenario planning method and the CSF method support strategic decision-making by strengthening the ability to make good, information-based decisions, which strengthens the decisions and strategies themselves [Conway 2004].

Boynton and Zmud noted that "any association between CSFs and organizational success may not represent a true causal relationship." They also underscored that CSFs can never be scientifically credited with positive outcomes. [Boynton 1984]. Van der Heijden notes that "the quality of the decision [or strategy] cannot be measured by reference to outcome, but only on the basis of how it was arrived at" [van der Heijden 1996]. In other words, decisions and strategies can really only be measured by the process that generated them-it is impossible to measure a strategy by its outcome. In fact, all planning methods (strategic planning, the critical success factor method, and scenario planning) have this limitation and cannot guarantee success.

Similarly, Schwartz and van der Heijden both explain that there is no precise method for extracting a single, explicit, or "winning" strategy from a set of future scenarios. Noting humorist Garrison Keillor's Lake Wobegon paradox-“where all the kids are above average"-Gregory et al. point out that a foolproof tool for generating winning strategies would lead to a paradoxical situation where all strategies (even competing ones) would be winners [Gregory 1998]. And so, scenarios are not a means to a strategy, but a means to a strategic conversation, which should lead to smart strategic decision-making.

While neither CSFs, scenarios, nor strategic planning itself guarantee the development of an explicitly correct strategy, they provide information that supports good decision-making. Both the critical success factor method and the scenario planning method are well-defined approaches that have been shown to be effective [Caralli 2004, van der Heijden 1996]. It is important to remember that care must be taken with both methods to produce valid and useful results. When the methods

are used together and integrated with a strategic planning method, even greater care must be taken to ensure that the integrity of the various methods is maintained and the results are valid. Nonetheless, a substantially enriched strategic thinking process can be attained.

\subsection{Future Work}

CSFs and scenario planning are excellent techniques for managing operational commitments and managing the uncertain future. Combining these techniques in a strategic planning effort have demonstrated viability and produced a strategic planning framework. The following additional tasks would enrich the current work:

- Explore the use of IT or security scenarios. Because of the value scenarios bring to decision making, IT, security, or other operational-level scenarios are likely assets in unit-level planning (IT strategy or security strategy) and organizational strategic planning. 
- Create an integrated strategic planning process. The strategic planning framework described in this document has established a way to integrate the data created by a strategic planning process, the CSF method, and scenario planning. This work also showed that a typical strategic planning process could be enhanced by augmenting it with the CSF and scenario methods; however, an integrated process remains undefined. This integration will vary with different strategic planning approaches, but the integration need not be complicated, only explicit. A robust strategic planning process/methodology that includes strategic thinking, regular reviews, and a solid documentation approach is strongly indicated. Future work should support the codification, use, and refinement of a strategic thinking and planning process.

- Connect CSFs and scenarios directly to one another in the monitoring stages of an integrated strategic planning process. Implementation of a strategic plan, coupled with review and maintenance of the strategy to ensure that they stay relevant over time, are critical components of strategic planning and are not covered in this report. Both the critical success factor method and the scenario planning method stress the importance of maintenance and provide fitting maintenance techniques. There may be a way to connect CSFs and scenarios directly to one another in the monitoring stages of an integrated strategic planning process. Strategic management techniques, such as the balanced scorecard, could provide a mechanism for monitoring overall performance of an integrated set of strategic indicators (e.g., goals, critical success factors, and early warning signs). 


\section{Appendix A CSF Method Application Notes}

The simple nature and broad applicability of CSFs lead to a variety of ways in which they can be used and misused. ${ }^{31}$ We found that each aspect of the method, though controllable, is inherently subjective, and subject to error. The following sections address some of the issues associated with the method and provide some recommendations and guidelines for addressing those issues.

\section{Qualifying the Application}

An organization that does strategic planning well is a good candidate for the CSF technique. It is essential to look at critical success factors in the context of an entire strategic planning effort, rather than as a stand-alone endeavor. Ideally, an organization's mission, vision, and current goals will be articulated and well understood prior to launching a CSF activity. In addition, much of the information collected in the context of critical success factor interviews will be inherently outside the scope of critical success factors, despite careful questioning and attention to keeping respondents on track. For example, we gathered rich information regarding recommendations, visions, measurements, goals, and values. All the information was captured as potentially (and eventually) valuable input, but much of the data did not relate to critical success factors. A solid strategic planning method, such as the one described by Fogg in Team-Based Strategic Planning: A Complete Guide to Structuring, Facilitating, and Implementing the Process, can provide ready receptors for non-CSF oriented information [Fogg 1994].

If an organization is not adept at strategic planning, it is highly recommended that basic strategic planning groundwork is laid first. CSFs can then be brought in to extend and improve the organization's understanding of its operational and competitive self.

\section{CSF Interviews}

The interview process, like the CSF method, is simple and can be used much more broadly than for developing CSFs alone. ${ }^{32}$ Bullen and Rockart's approach to interviewing individuals was to collect individual CSFs that could be viewed as a group, wherein consistently referenced ideas could be extracted and refined into a set of organizational CSFs [Bullen 1981]. But (and Rockart encourages this) the CSF-style executive interviews can be used to elicit other insightful information, including goals, guiding principles, barriers, visions, measures, and more. Information beyond the scope of CSFs can be collected via these interviews either explicitly or by accident. Open-ended questions like those used in the CSF method elicit free-form data that can be off topic - and useful, or not. When recognized, the expansion of an interview question or answer can

\footnotetext{
31 In their assessment of the CSF method, Boynton and Zmud examined the previously cited difficulty of using the CSF method and concluded that the method should be directed by a skilled analyst [Boynton 1984].

32 Bullen and Caralli provide good detail about how to formulate interview questions and conduct CSF interviews [Bullen 1981, Caralli 2004]. This material is worth studying.
} 
yield exceptionally useful information; alternately, it can muddy an already challenging pool of information. (See the section below titled "Pre-Screening Activity Statements.")

Bullen and Rockart recommend the lively, energetic participation of the interviewer [Bullen 1981]. Caralli, on the other hand, recommends a more neutral and detached interview approach [Caralli 2004]. Both approaches can be successful, but a good understanding of the interview style will help ensure that the collected data is handled appropriately. Boynton and Zmud examined the potential for introducing bias through the interview process. They concluded only that a skilled CSF analyst would yield consistent results with another skilled analyst, implying, once again, the need for competence with the method [Boynton 1984].

To communicate the intention and set an appropriate context for a brief and productive interview, we provided a single-sheet description of CSFs, the interview process, and our intentions regarding the interview, to each interviewee. This seemed to help the interviewees feel comfortable and prepared.

\section{CSF Interview Data}

Caralli's CSF method recommends creating activity statements as an initial step in deriving CSFs. He recommends deriving activity statements from organizational documents-mission statement, vision statement, goals and objectives - in addition to the raw interview material. Depending on the scope of the effort and the number of interviewees, the resulting set of activity statements can get very large.

In a project to help a major federal agency develop organizational and IT CSFs, we interviewed 34 senior executives. We found that with a very large data set, affinity grouping can be ineffective. ${ }^{33}$ The sheer volume of activity statements can make the evaluation of each one very shallow. In our experience, keyword groups (rather than true affinity groups) tended to form and the emergent themes and CSFs became very generic. The real information was lost to simplistic ideas.

\section{Pre-Screening Activity Statements}

Tagging and pre-screening the activity statements, particularly in a large data set, helps organize the data prior to the affinity grouping step. Activity statements can be tagged and grouped by source (organizational unit, for example) or topic. Interview data that is explicitly outside the scope of CSFs (e.g., visioning responses) should also be separated and tagged. Further, while unsolicited information is common and can be very valuable, some information is simply irrelevant. That data should be removed from consideration even if activity statements can be derived from it. The affinity grouping technique is much more effective on high-quality, manageable, data.

${ }^{33}$ In this engagement, we conducted 34 interviews with executives using Caralli's question set plus one additional question about the future. The interview data alone yielded 625 activity statements. This large number of interviewees ultimately made the CSF development process very difficult, but the intention was to get buy-in from a strong representation of senior staff. 


\section{Deriving CSFs}

Caralli writes, "The fact that CSFs can be defined in so many different ways speaks to their elusive nature" [Caralli 2004]. He is quite right; CSFs are simple in nature, broadly defined, and elusive. Rockart called CSFs "a subjective judgment arrived at only after some thought," adding that there is no clear algorithm for finding them [Rockart 1979]. Boynton and Zmud examined the previously cited weakness, and concluded that although the CSF method may yield simple and thought-provoking information, the information may not accurately represent the environment from which it is drawn [Boynton 1984]. Several issues associated with CSF derivation are addressed below.

\section{CSF Form}

Caralli's CSF method description contains the following footnote: "Some organizations may decide to conclude the CSF method at the point of development of supporting themes. In some cases, supporting themes may already fit the description of a critical success factor. However, this will result in a generous number of CSFs. Whether this is acceptable for an organization depends on how they will eventually use the CSFs. Abstracting from supporting themes to a smaller set of CSFs is a way to manage the number of CSFs derived, but may not be useful for all organizations" [Caralli 2004, Appendix A].

Caralli's method concludes with the formulation of a small number of briefly stated CSFs. For strategic planning, we found the supporting-theme version of the CSFs to be more useful because the meaning of the statements was contained in the details. We also found that for strategic planning, supporting information is worth retaining and adds value to the CSF statements. ${ }^{34}$

\section{CSF Criteria}

Caralli outlines the qualities of good CSFs [Caralli 2004]. We found the information useful and created a CSF criteria checklist, summarized below:

- Does the CSF represent ongoing activity (rather than a one-time event)?

- Is performance of the CSF essential to the organization's survival?

- Does the CSF encapsulate a single idea (as opposed to a compound, or multiple ideas)?

- Does the CSF state what to do (rather than how to do it)?

- Does the CSF represent something other than values, goals, or mission statements?

\section{Non-CSFs}

Clear integration of the CSF method with a coherent strategic planning process is necessary so that CSFs not only integrate well with the strategic plan, but so that the non-CSF information that is elicited during interviews can be accurately identified and utilized. As mentioned above, the simplicity, power, and potential breadth of a CSF interview allows for wide data collection, inten-

\footnotetext{
${ }^{34}$ For our use in strategic planning, "CSF statement" corresponds to what Caralli called a "supporting theme," and is the final form of a CSF.
} 
tionally or not. A solid strategic planning process and a good understanding of all strategic plan elements helps ensure that data is used appropriately. When the CSF method is used in isolation or without explicit integration with the larger strategic planning method, it becomes difficult to filter the data. The fact that information is true and interesting does not necessarily make it a CSF.

\section{Guidelines for Using the CSF Method}

Shank et al. offer six guidelines for using the CSF method that resonate with our experience:

- Use a formal method precisely.

- Understand the business.

- Ensure senior sponsorship.

- Educate staff and interviewees.

- Avoid premature linking to the current IT state.

- $\quad$ Derive CSFs from multiple organizational levels [Shank 1985].

Boynton and Zmud examined the strengths and weaknesses of the CSF method as Rockart defined it. They found the following:

- The CSF method can generate acceptance at the senior levels.

- The method facilitates structured analysis and planning.

- The method is difficult to use.

- Valid results require skilled analysts.

- The method can yield simple results that don't accurately represent a complex environment [Boynton 1984].

Boynton and Zmud also provided insightful guidelines for applying the method in an IT context. Familiarity with these resources is recommended. 


\section{Appendix B Scenario Planning Application Notes}

Although scenario building is compelling and enjoyable work, it is not easy. Familiarity with the scenario method and the nature of scenarios, as well as skilled facilitation, are critical to creating useful scenarios. The following sections address some of the issues associated with scenario development and provide some recommendations and guidelines for addressing those issues.

\section{Qualifying the Application}

Scenario planning is best applied to organizations facing important issues where there are significant uncertainties; however, it isn't always appropriate to use scenarios in strategic planning. Broad change is occurring today at an incredibly fast pace in almost every facet of business. As a result, many organizations are nearly consumed by the present alone. Some organizations simply will not have the ability to imagine the future. Those that are overwhelmed by basic planning or current struggles will not necessarily have the capacity for strategic thinking or scenario thinking.

\section{Scenario Workshops}

While it can be invigorating to complete the full set of scenario-development steps over several consecutive days, that format rarely allows for deep thought, and can cause organizations to lose, or fail to collect, important information. We found that the scenario-development steps lend themselves easily to a set of step-specific workshops spread out over time (perhaps several weeks). After an organization identifies a focal issue, which can be done by the sponsor with help from workshop facilitators, we recommend conducting several two- to four-hour bounded workshops in which participants

1. Identify the primary driving forces in the local environment.

The identification of driving forces in the macro environment can be done by key stakeholders in a brainstorming setting or by the scenario consultants with assistance from one or two representatives of the organization.

2. Identify critical uncertainties and select scenario logics.

This step can be done rather quickly by asking participants to rank importance and uncertainty either in a group session or as an off-line exercise. Either way, it is useful to get a broad perspective on these determinations. The sponsor, with help from the scenario consultant, is ultimately responsible for selecting the scenario logics.

3. Flesh out the scenarios.

The task of building the scenarios works quite well when the groundwork of the previous steps is well-laid. When participants come to a scenario-building workshop fresh and prepared, the results can be extraordinary. 
4. Identify robust scenarios and indicators.

A small executive team is best suited for selecting robust scenarios and identifying indicators to monitor.

Time to think, coupled with documentation of interim results from a small workshop, can pay dividends. ${ }^{35}$ Organizations should also expect to spend time with the scenarios after they are developed, further discussing them and vetting the scenarios and the strategies.

Scenario development and strategic conversations are an inherently creative - and fun — process. Although many planning processes benefit from participation across the layers of the organization, we found that a hierarchical mix drew stifled outputs, possibly because of a reluctance to take risks when superiors or subordinates are present. It may, however, be beneficial to include external domain experts and customers in scenario exercises.

The SEI has not pursued the interview-based method of developing scenarios that van der Heijden describes [van der Heijden 1996].

\section{Scenario Output}

Ideas flow quickly and furiously in scenario planning when things go well. Capturing the proceedings and results of a scenario workshop is invaluable. Considerable effort should also be anticipated for post-processing - the scenarios must be written down to be useful. A special effort should be made to capture the stories that come out of the workshop, as these are the essence of the scenarios.

35 Schoemaker also recommends a slow process that allows for thinking time, rather than a "get it done" approach, for scenario development [Schoemaker 1998]. 


\section{Appendix C Glossary}

\section{Action}

A specific step to achieve a goal or objective. An action typically has assigned staff and schedule constraints.

\section{Barrier}

An external condition or organizational (internal) weakness that hinders an organization's ability to accomplish a goal or objective.

\section{Critical Success Factors (CSFs)}

The handful of key areas where an organization must perform well on a consistent basis to achieve its mission.

\section{Enabler}

An external condition or organizational strength that facilitates an organization's ability to accomplish its goals or objectives.

\section{Future Scenarios}

Multiple plausible futures that may develop due to external forces. Where a vision articulates a "preferred future," future scenarios taken together describe how, given different circumstances or environments, an organization might achieve its mission.

\section{Goals}

Broad, high-level aims that support the accomplishment of a mission.

\section{Guiding Principles}

Directive statements that articulate the constraints an organization chooses to place upon the way it achieves its goals. Guiding principles embrace core values and are used to shape an organization's strategy. Guiding principles reflect long-term intentions, but are not necessarily permanent.

\section{Information Systems (IS)}

The means by which people and organizations gather, process, store, use, and disseminate information.

\section{Information Technology (IT)}

The hardware, software, and telecommunications that facilitate the acquisition, processing, storage, delivery, and sharing of information and other digital content in an organization. Also, the use of computing, electronics, and telecommunications technology in managing and processing information, especially in large organizations.

\section{Initiative}

A specific set of actions that implement a strategy. 


\section{IT Strategy}

A description of how information technology will support an organization's overall business strategy.

\section{Mission}

The primary business or purpose of an organization.

\section{Objectives}

Specific, quantifiable, lower-level targets that indicate accomplishment of a goal.

\section{Operational Planning}

The process of making decisions about the allocation of organizational resources (capital and staff) to pursue a strategy.

\section{Performance Measure}

Performance targets relevant to each objective.

\section{Strategic Goal}

A primary goal of an organization or enterprise that implies a particular strategy or set of strategies.

\section{Strategic Plan}

A document that results from a strategic planning activity. It elaborates the organizational strategy and documents the elements that influence it.

\section{Strategic Planning}

A process for defining an organization's strategy, or direction, and making decisions about how to allocate its resources to pursue this strategy, including its capital and people.

\section{Strategy}

A derived approach to achieving the mission, goals, and objectives of an organization. It supports the organizational vision, takes into account organizational enablers and barriers, and upholds guiding principles.

\section{Sub-Goal}

A logical decomposition of a broader goal.

\section{Vision}

An ideal an organization intends to pursue. It links the organization to the future by articulating instantiations of successful execution of the mission. 


\section{References}

\section{[Anthony 1972]}

Anthony, Robert N.; Dearden, John; \& Vancil, Richard F. Management Control Systems. Homewood, Illinois: R. D. Irwin, 1972. 147-158.

\section{[Bernard 2005]}

Bernard, Scott A. An Introduction to Enterprise Architecture. 2nd ed. Bloomington: AuthorHouse, 2005.

\section{[Boynton 1984]}

Boynton, Andrew C. \& Zmud, Robert W. "An Assessment of Critical Success Factors.” Sloan Management Review 25 (1984): 17-27.

\section{[Bullen 1981]}

Bullen, Christine V. \& Rockart, John F. "A Primer on Critical Success Factors.” Center for Information Systems Research, Sloan School of Management, Massachusetts Institute of Technology, 1981.

\section{[Caralli 2004]}

Caralli, Richard A. The Critical Success Factor Method: Establishing a Foundation for Enterprise Security Management (CMU/SEI-2004-TR-010). Software Engineering Institute, Carnegie Mellon University, 2004. www.sei.cmu.edu/library/abstracts/reports/04tr010.cfm

\section{[Cassidy 2006]}

Cassidy, Anita. A Practical Guide to Information Systems Strategic Planning. 2nd ed. Boca Raton, Florida: Auerbach Publications, 2006.

\section{[Conway 2004]}

Conway, M. "Scenario Planning: An Innovative Approach to Strategy Development." Swinburne University of Technology, 2004.

\section{[Daniel 1961]}

Daniel, D. Ronald. "Management Information Crisis," Harvard Business Review, Sept.-Oct. (1961).

\section{[Dobbins 1998]}

Dobbins, James H. \& Donnelly, Richard G. "Summary Research Report on Critical Success Factors in Federal Government Program Management." Acquisition Review Quarterly (1998): 61-82.

\section{[Fahey 1997]}

Fahey, Liam \& Randall, Robert, eds. Learning from the Future. John Wiley \& Sons, 1997.

\section{[Fogg 1994]}

Fogg, Davis C. Team-Based Strategic Planning: A Complete Guide to Structuring, Facilitating, and Implementing the Process. New York: AMACOM/American Management Association, 1994. 


\section{[Gregory 1998]}

Gregory, Erika; Harris, Gerald; \& Ogilvy, Jay. "After the Scenarios, Then What? Strategic Conversation, Early Indicators, and the Art of Communication Scenarios." Presearch. Provoking Strategic Conversation 2, 1 (1998).

\section{[Gunasekaran 2004]}

Gunasekaran, Suresh \& Garets, Dave. "Managing the IT Strategic Planning Process," 22-34. Healthcare Information Management Systems Cases, Strategies, and Solutions. M. Ball, C.M. Weaver, and J. M. Kiel, ed. Springer, 2004.

\section{[Hamel 1996]}

Hamel, Gary. "Strategy as Revolution.” Harvard Business Review (1996): 69-82.

\section{[Heracleous 1998]}

Heracleous, Loizos. "Strategic Thinking or Strategic Planning." Long Range Planning 31 (1998): 481-87.

\section{[Heracleous 2003]}

Heracleous, Loizos. Strategy and Organization: Realizing Strategic Management. Cambridge University Press, 2003.

\section{[Kessler 2000]}

Kessler, Thomas \& Kelley, Patricia. The Business of Government: Strategy, Implementation \& Results. Management Concepts, 2000.

\section{[Leadership Strategies 2007]}

Leadership Strategies, Inc. "Strategic Planning: The Drivers Model.” Leadership Strategies 30 (2007).

\section{[Liedtka 1998]}

Liedtka, Jeanne M. "Strategic Thinking: Can it be Taught?” Long Range Planning 31 (1998): $120-29$.

\section{[ManyWorlds 2002]}

ManyWorlds, Inc. "Grasping the Future: Comparing Scenarios to Other Techniques."

\section{[Mintzberg 1994]}

Mintzberg, Henry. "The Fall and Rise of Strategic Planning." Harvard Business Review, JanuaryFebruary (1994): 107-114.

\section{[Ogilvy 2004]}

Ogilvy, Jay \& Schwartz, Peter. "Plotting Your Scenarios.” Global Business Network, 2004.

\section{[Porter 1996]}

Porter, Michael E. "What is Strategy?" Harvard Business Review, November-December (1996): 61-78.

\section{[Raynor 2007]}

Raynor, Michael E. The Strategy Paradox: Why Committing to Success Leads to Failure (and What to Do About It). New York: Doubleday, 2007. 


\section{[Rockart 1979]}

Rockart, John F. "Chief Executives Define Their Own Data Needs." Harvard Business Review (1979): 81-92.

\section{[Schoemaker 1998]}

Schoemaker, Paul J. H., Ch. 26, "Twenty Common Pitfalls in Scenario Planning." Learning from the Future, John Wiley and Sons, 1998.

\section{[Schwartz 1996]}

Schwartz, Peter. The Art of the Long View: Planning for the Future in an Uncertain World.

Currency Doubleday, 1991.

\section{[Shank 1985]}

Shank, Michael E.; Boynton, Andrew C.; \& Zmud, Robert W. "Critical Success Factors as a Methodology for MIS Planning.” MIS Quarterly 9, 2 (1985): 121-129.

\section{[Shell 2005]}

Shell International Limited. "Shell Global Scenarios to 2025.” 2005.

\section{[Sherwood 2007]}

Sherwood, Dennis. "Turning Innovative Scenarios into Robust Strategies." The Systems Thinker 18, 5 (March 2007): 2-7.

\section{[Thompson 1967]}

Thompson, James D. Organizations in Action. McGraw-Hill, 1967.

\section{[USPS 2000]}

United States Postal Service. Five-Year Strategic Plan FY 2001-2005 (2000).

http://www.usps.com/strategicplanning/_pdf/fiveyear.pdf

\section{[van der Heijden 1996]}

van Der Heijden, Kees. Scenarios: The Art of Strategic Conversation. John Wiley \& Sons Limited, 1996.

\section{[Ward 2002]}

Ward, John \& Peppard, Joe. Strategic Planning for Information Systems. John Wiley \& Sons. Ltd., 2002.

\section{[Wilkinson 1995]}

Wilkinson, Lawrence. "How to Build Scenarios." Wired (1995): 74-81. 


\begin{tabular}{|c|c|c|c|c|}
\hline \multicolumn{3}{|c|}{ REPORT DOCUMENTATION PAGE } & \multicolumn{2}{|c|}{$\begin{array}{l}\text { Form Approved } \\
\text { OMB No. 0704-0188 }\end{array}$} \\
\hline \multicolumn{5}{|c|}{$\begin{array}{l}\text { Public reporting burden for this collection of information is estimated to average } 1 \text { hour per response, including the time for reviewing instructions, search- } \\
\text { ing existing data sources, gathering and maintaining the data needed, and completing and reviewing the collection of information. Send comments regard- } \\
\text { ing this burden estimate or any other aspect of this collection of information, including suggestions for reducing this burden, to Washington Headquarters } \\
\text { Services, Directorate for information Operations and Reports, } 1215 \text { Jefferson Davis Highway, Suite } 1204 \text {, Arlington, VA 22202-4302, and to the Office of } \\
\text { Management and Budget, Paperwork Reduction Project (0704-0188), Washington, DC 20503. }\end{array}$} \\
\hline $\begin{array}{l}\text { 1. AGENCY USE ONLY } \\
\text { (Leave Blank) }\end{array}$ & \multicolumn{2}{|c|}{$\begin{array}{ll}\text { 2. } & \text { REPORT DATE } \\
& \text { November } 2010\end{array}$} & \multicolumn{2}{|c|}{$\begin{array}{l}\text { 3. REPORT TYPE AND DATES } \\
\text { COVERED } \\
\text { Final }\end{array}$} \\
\hline \multicolumn{3}{|c|}{$\begin{array}{l}\text { Strategic Planning with Critical Success Factors and Future Scenarios: An Integrated Strategic } \\
\text { Planning Framework }\end{array}$} & \multicolumn{2}{|c|}{$\begin{array}{l}\text { 5. FUNDING NUMBERS } \\
\text { FA8721-05-C-0003 }\end{array}$} \\
\hline \multicolumn{5}{|c|}{$\begin{array}{ll}\text { 6. } & \text { AUTHOR(S) } \\
& \text { Linda Parker Gates }\end{array}$} \\
\hline \multicolumn{3}{|c|}{$\begin{array}{l}\text { 7. PERFORMNG ORGANIZATION NAME(S) AND ADDRESS(ES) } \\
\text { Software Engineering Institute } \\
\text { Carnegie Mellon University } \\
\text { Pittsburgh, PA } 15213\end{array}$} & \multicolumn{2}{|c|}{$\begin{array}{l}\text { 8. PERFORMNG ORGANZATION } \\
\text { REPORT NUMBER } \\
\text { CMU/SEI-2010-TR-037 }\end{array}$} \\
\hline \multicolumn{3}{|c|}{$\begin{array}{l}\text { 9. SPONSORING/MONTORING AGENCY NAME(S) AND ADDRESS(ES) } \\
\text { HQ ESC/XPK } \\
5 \text { Eglin Street } \\
\text { Hanscom AFB, MA 01731-2116 }\end{array}$} & \multicolumn{2}{|c|}{$\begin{array}{l}\text { 10. SPONSORING/MONTORING } \\
\text { AGENCY REPORT NUMBER } \\
\text { ESC-TR-2010-102 }\end{array}$} \\
\hline \multicolumn{5}{|c|}{ 11. SUPPLEMENTARY NOTES } \\
\hline \multicolumn{3}{|c|}{$\begin{array}{l}\text { 12A DISTRIBUTIONAVALABIUTY STATEMENT } \\
\text { Unclassified/Unlimited, DTIC, NTIS }\end{array}$} & \multicolumn{2}{|c|}{ 12B DISTRIBUTIONCODE } \\
\hline \multicolumn{5}{|c|}{$\begin{array}{l}\text { This report explores the value of enhancing typical strategic planning techniques with the critical success factor (CSF) method and sce- } \\
\text { nario planning. It synthesizes documented theory and research in strategic planning, CSFs, and future scenarios. It proposes an en- } \\
\text { hanced, integrated information framework for strategic planning that can help organizations understand the broad range of interrelated } \\
\text { elements that influence strategy development. Finally, the report provides insights and lessons regarding the value and limitations of the } \\
\text { integrated strategic planning framework and suggestions for future work. }\end{array}$} \\
\hline \multirow{2}{*}{\multicolumn{3}{|c|}{$\begin{array}{l}\text { 14. SUBJECT TERMS } \\
\text { strategic planning, critical success factors, scenario-based planning, future scenarios, IT strat- } \\
\text { egy } \\
\text { 16. PRICECODE }\end{array}$}} & \multicolumn{2}{|c|}{$\begin{array}{l}\text { 15. NUMBEROF PAGES } \\
67\end{array}$} \\
\hline & & & \multicolumn{2}{|c|}{ 16. PRICECODE } \\
\hline $\begin{array}{l}\text { 17. SECURITY CLASSIFCATION OF } \\
\text { REPORT } \\
\text { Unclassified }\end{array}$ & $\begin{array}{l}\text { 18. SECURITY CLASSIFCATION } \\
\text { OFTHISPAGE } \\
\text { Unclassified }\end{array}$ & $\begin{array}{l}\text { 19. SECURITY CLASS } \\
\text { OF ABSTRACT } \\
\text { Unclassified }\end{array}$ & ICATION & $\begin{array}{l}\text { 20. LMTATIONOF } \\
\text { ABSTRACT } \\
\text { UL }\end{array}$ \\
\hline
\end{tabular}

